\title{
A sustainable sourcing competence model for purchasing and supply management professionals
}

\author{
Heike Schulze $e^{1,2} \cdot$ Lydia Bals $^{1,3,4} \cdot$ Jon Warwick ${ }^{2}$
}

Received: 5 August 2021 / Revised: 19 November 2021 / Accepted: 1 February 2022 / Published online: 7 March 2022

(c) The Author(s) 2022

\begin{abstract}
In order to implement sustainability standards in practice, capabilities are needed at the organizational level as well as at the individual level. The presented sustainable purchasing and supply management (SPSM) competence model is based on the combination of a systematic literature review (SLR) and a Delphi study. The competence model outlines specific SPSM competences which are divided into functional-oriented, cognition-oriented, social-oriented and meta-oriented competence clusters. We also discuss their applicability during typical purchasing and supply management processes. Each of the 26 competences is presented with a short definition as well as exemplary behaviors. For research on SPSM from an organizational point of view, the analysis of the relevance of competences with regard to purchasing process stages offers a conceptual basis for bringing sustainability into overall PSM models, instead of positioning sustainability as an 'add-on' activity, which risks the potential of sustainability issues becoming marginalized. The resulting SPSM competence model can serve as a basis for improving teaching and training in both higher education and professional training contexts. In practice, it can also serve to aid the selection of new employees, evaluate employee performance, create development plans or build HR systems.
\end{abstract}

Keywords Competences $\cdot$ Purchasing and supply management $\cdot$ Sustainability

\section{Introduction}

Purchasing and Supply Management (PSM) has been recognized as a key determinant of business competitiveness since it has been established that an organization's external costs, i.e. those monies being paid to suppliers, can represent some 60 to 80 percent of total costs (Monczka et al. 2016; Van Weele 2010). This being the case, it has become vital that the contribution that PSM can make in establishing effective working practices across organizational boundaries and in managing external networks should be explored (Van

Lydia Bals

lydia.bals@hs-mainz.de; lb.si@cbs.dk

1 Mainz University of Applied Sciences, Lucy-Hillebrand-Str. 2, 55128 Mainz, Germany

2 London South Bank University, 103 Borough Road, London SE10AA, UK

3 EBS University for Business and Law, Oestrich-Winkel, Germany

4 Copenhagen Business School (CBS), Kilevej 14, 2. Floor, 2000 Frederiksberg, Denmark
Weele 2014). In this paper, we refer to the PSM discipline as being focused on the upstream supply network.

The expected performance of PSM depends on organizational maturity and on employee competences. A review of the literature confirms that there has been some considerable research relating to the skills, competences and knowledge required in PSM (e.g. Giunipero et al. 2006; Faes et al. 2001; Giunipero et al. 1999, 2005; Giunipero and Pearcy 2000; Kern et al. 2011; Knight et al. 2014), but in a business environment where change can be fast-paced (for example through developing digital technologies) or in which external system shocks can be highly disruptive (the global pandemic being a case in point) it is important to continually take stock of the competence requirements required to meet such developments. More specifically, examples of such developments would include: sourcing innovation (Luzzini et al. 2015; Schiele 2010, 2012), handling potential supplier disruptions (Wieland et al. 2016), ensuring sustainability in the supplier network (Montabon et al. 2016; Schneider and Wallenburg 2012; Wilding et al. 2012) and the implications of technology-based workplace changes due to increased digitization. While the existing PSM literature has explored those capabilities necessary to meet a range of organizational 
performance measures (e.g. Gonzalez-Benito 2007; Krause et al. 2001), it is becoming clear that digitalization, innovation and sustainability are becoming increasingly important (Bals et al. 2019).

In terms of sustainability, the expectation towards companies is that their ability to achieve sustainability goals should be improving. The United Nations Economic and Social Council regards sustainable development as the international community's most urgent priority and has called for action across all three pillars of sustainable development economic, social and environmental (United Nations 2020). The UN Sustainable Development Goals, adopted by the UN member states in (2015), reflect that businesses must embed sustainability values within their value chains arguing that the impact on the environmental and social pillars may be enhanced through business opportunities both upstream and downstream in the value chain (UNGC, GRI, WBSC 2015).

At the same time, civil society and practitioners still emphasize sustainable supply chain management being one of the major challenges to reach the UN Sustainable Development Goals. In 2019, the European Commission undertook a study of due diligence requirements throughout the supply chain. The results that were published in 2020 (European Commission [EC] 2020) commented that "[j] ust over one-third of business respondents indicated that their companies undertake due diligence which takes into account all human rights and environmental impacts, and a further one-third undertake due diligence limited to certain areas. However, the majority of business respondents which are undertaking due diligence include first tier suppliers only. Due diligence practices beyond the first tier and for the downstream value chain were significantly lower" (EC 2020, p. 16). Moreover, those companies that intend to cascade sustainability requirements throughout their supply chains and which have established due diligence processes and tools nevertheless struggle to do so successfully (UNGC 2017; Villena 2019).

When looking at the downstream value chain, PSM departments within companies play a key role in engendering sustainability values and practices (Walker and Brammer 2012; Yawar and Seuring 2018),). In terms of what is driving sustainable purchasing and supply management (SPSM) implementation in purchasing, there are both organizational and individual factors influencing how, for example, tradeoffs between short term economic goals and sustainability criteria are being dealt with when purchasing decisions are made (Goebel et al. 2018). Considerable PSM research has already looked at the organizational capabilities for Sustainable Purchasing and Supply Management (SPSM) implementation (Carter 2005; Giunipero et al. 2012; Marshall et al. 2015; Preuss 2009) and the reasons for a lack of practical implementation of sustainable practices in supply networks have been discussed from different perspectives. For example, it has been argued that sustainability aspects might be insufficiently embedded into business purpose and processes (Aguinis and Glavas 2013; Bals and Tate 2018; Bocken et al. 2014; Harms et al. 2013), or that leadership support for implementation of sustainability related regulation is lacking (Etse et al. 2021). Other studies have identified the complexity and lack of transparency of supply networks as being a constraint on the implementation of SPSM. In relation to this last point Fraser et al. (2020a, b), in their study on traceability and transparency in the Cobalt supply chain, found that actors in the supply chain very often struggle with the complexity in mapping the supply chain even before setting up due diligence tools.

Villena (2019) found that PSM functions within companies are often left out of the implementation process of sustainability requirements, although they play a key role in engendering sustainability values and practices in firms and across supply chains (Walker and Brammer 2012; Yawar and Seuring 2018). PSM has been traditionally rewarded mainly for creating financial value (Monczka et al. 2016). The handling of social or environmental issues is still often considered as an additional task (Caniato et al. 2012; Pagell and Shevchenko 2014), although there has already been an increasing emphasis on embedding sustainability consistently throughout PSM processes (Johnsen et al. 2014). Still, the effective and efficient integration of sustainability in PSM processes remains a challenge. Fraser et al. (2020a, b), for example, reported how a standardization and crossrecognition of sustainability audits can help overcome overload in purchasing organizations and avoid audit fatigue on the supplier side.

From an individual perspective, practitioners increasingly recognize the role that buyers play to implement SPSM. Being the individual actors in purchasing organizations, purchasing professionals need to fulfil the role in their daily job tasks. Both from a private and public procurement perspective, education for buyers is emphasized as a factor to improve SPSM implementation, e.g. to enable buyers to modify tenders and requests for proposals according to sustainability requirements, and to support them in applying new approaches to supplier relationship management that include sustainability components. Still, previous research has shown that there is a lack of individual training for purchasing professionals to enable them to implement SPSM (Villena 2019), and even less is known about the individual competences required to successfully manage sustainability aspects in a purchasing role. Although there has been some research into competences for sustainability/CSR professionals (Osagie et al. 2016; Willard et al. 2010), and engineering professionals (Hanning et al. 2012) and sustainable management competences (Galleli and Hourneaux 
Junior 2020, 2019), PSM research on the individual factors which drive SPSM behavior is less comprehensive, and the individual PSM employee perspective for SPSM implementation is rarely taken (Pagell and $\mathrm{Wu} 2009$ ).

Therefore, this paper aims to fill the gap in existing research identifying those individual sustainability competences required for SPSM behavior. The aim is to enrich the discussion on how to overcome the struggle to implement SPSM within PSM organizations by shedding light on the individual competences required for SPSM. This research focuses on the social and environmental aspects of sustainability, with the primary research question "Which individual competences of PSM professionals are required to implement SPSM?" and presents a competence model developed to answer the research question. A competence model describes competences that are required for a job or a position (Mansfield 1996; Dalton 1997; Spencer and Spencer 1993; Krumm et al. 2012). Individuals who act based on competences which are described in a competence model should be more successful compared to others in managing complex situations in a professional context (Krumm et al. 2012; Spencer and Spencer 1993). The SPSM competence model developed in this research provides a set of specific competences, together with descriptions of individual behavior that corroborates a SPSM competence. The study contributes to research by shedding light on a rather new research field and forms a basis for various options for future research, which are discussed at the end of the paper. It complements the academic discourse on individual PSM and on SCM competences by adding the SPSM competence set.

This paper represents the conclusion of a series of articles and presents a competence model for SPSM.It builds on the results of a systematic literature review (SLR) and a Delphi study, which have already been published individually (Schulze and Bals 2020; Schulze et al. 2019), and for the first time fully presents 26 competences, each of them with a short definition as well as exemplary behaviors.

The remainder of the paper is organized as follows. The next section gives a short overview of the conceptual background and current state of research on SPMS competences. Next, the model development process is described, followed by the detailed SPSM competence model. The paper closes with conclusions, discussing implications, limitations and future research opportunities.

\section{Conceptual background}

\subsection{A definition of SPSM}

To clarify the unit of analysis for this work, the authors refer to Miemczyk et al. (2012, p. 489) who described SPSM as "the consideration of environmental, social, ethical and economic issues in the management of the organization's external resources in such a way that the supply of all goods, services, capabilities and knowledge that are necessary for running, maintaining and managing the organization's primary and support activities provide value not only to the organization but also to society and the economy". This definition was chosen because it embodies the sustainability perspective within the traditional description of PSM as a discipline (Van Weele 2010), reflecting an integrative perspective, and not considering sustainability as an add on or separate area for PSM.

\subsection{The procurement process}

To broaden the focus of the research to consider more than just the individuals working in PSM departments, a schematic procurement process as shown in Fig. 1 was used which includes source-to-contract process steps as well as the transactional purchase-to-pay aspects (Monczka et al. 2016; Van Weele 2014). Centers of competence shown in the middle of the figure refer to processes that are often performed in an overarching manner for the whole PSM function (Bals et al. 2018; O'Marah 2015). The descriptions of SPSM competences in the proposed competence model refer to specific tasks of purchasing professionals that are reflected in this process. In terms of who is performing the processes, the term 'PSM professionals' is used here in the sense of individuals operating with different responsibilities within a PSM function. The PSM professionals work within one or more of the source-to-contract, purchase-topay, or center of competence processes shown in Fig. 1. As outlined in the introduction, it is their behavior that either supports or hinders the attainment of sustainability goals of the organization.

\subsection{Competences and competence models}

While the PSM process can be clearly described, there is conceptual ambiguity around the definition of the term 'competence' in academic research and literature (Delamare LeDeist and Winterton 2005; Derwik et al. 2016; Erpenbeck 2013; Grote et al. 2012; Krumm et al. 2012; Salman et al. 2020; Shippmann et al. 2000). Despite this ambiguity, a broad based practical definition of 'competence' is adopted for this research which defines competence as "a set of abilities, skills and other attributes and characteristics that enable a person to manage complex situations effectively; this set can be developed through learning and experience" (Krumm et al. 2012, p. 3). In this definition, the term 'complex situation' is used to denote those situations which are not amenable to off-the-shelf solutions or recourse to general solution processes due to their specialized nature, complexity etc. 
Fig. 1 Purchasing and Supply Management processes ( adapted from Monczka et al. 2016; Van Weele 2014)

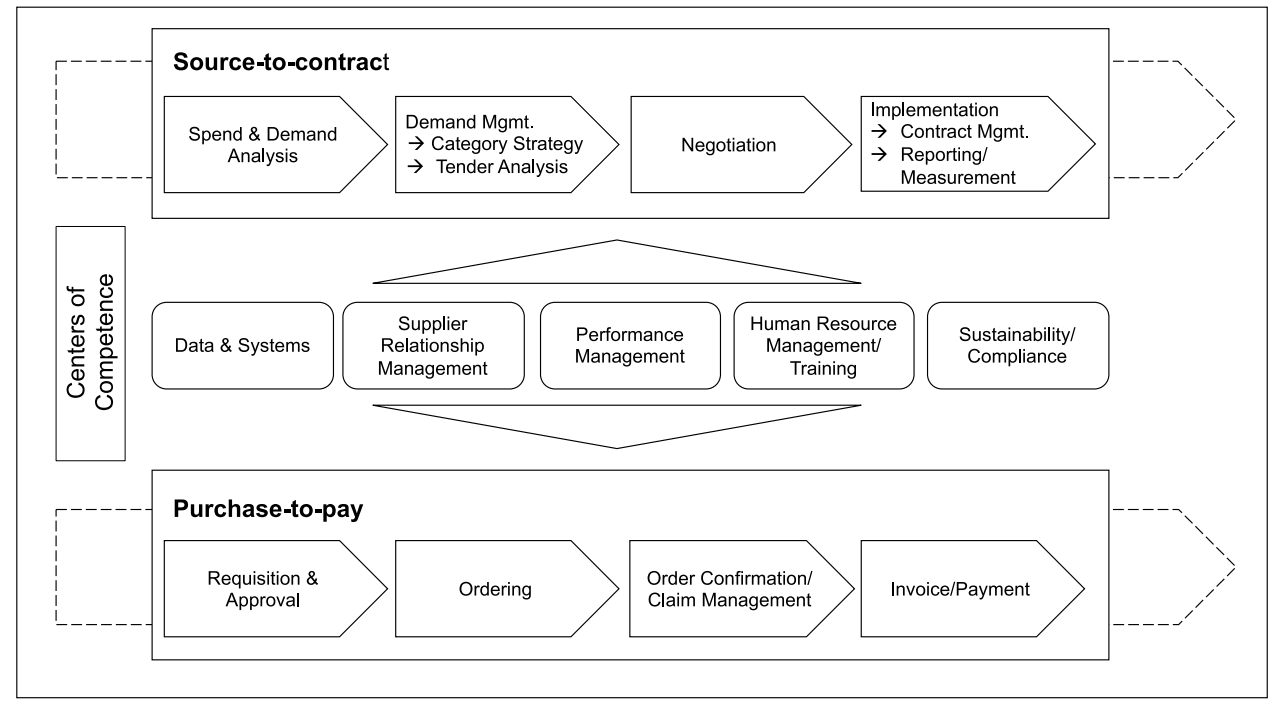

Based on the definition of Krumm et al. (2012), individual competences can be structured into a competence model. There has been some disagreement in literature on the term 'competence model', as most are more lists of competences than models. They do not elaborate on structures, competence hierarchies or interrelations (Dalton 1997; Krumm et al. 2012). Moreover, it is useful to differentiate between job descriptions or job analysis and competence models, while acknowledging that research does not provide unique and consistent differentiation criteria. In a rather condensed overview, Shippmann et al. (2000) indicated that job analysis is related to a specific job requirement whereas competence models have a broader focus. Also, competence models tend to relate more to strategic requirements (Krumm et al. 2012; Shippmann et al. 2000). Campion et al. (2011) found ten criteria differentiating competence models from job analysis. Some were common to those of Shippmann et al. (2000), e.g. competence models being linked to business objectives and strategies, or the way competence models describe the individual competences, while others mentioned by Campion et al. (2011) related to the impact of competence models on aspects of organizational change.

However, there are definitions of what a competence model represents, for example "A competency model is a detailed, behaviorally specific description of the skills and traits that employees need to be effective in a job" (Mansfield 1996, p. 7), or "A competency model depicts [...] motives, traits, and so forth as a set of desired job behaviors for a particular job position or level. A competency model also implies that such behaviors are predictive of who is likely to be successful in a position or role" (Dalton 1997, p. 48). Distilling these two descriptions, a competence model should describe competences that are required for a job or a position. Individuals who act based on competences which are described in a competence model should be more successful compared to others in managing complex situations in a professional context (Krumm et al. 2012; Spencer \& Spencer 1993). Further, competence models should inherently include a future perspective, aiming for competences that are relevant to the achievement of certain organizational goals (Briscoe and Hall 1999; Dalton 1997; Krumm et al. 2012). Organizations use competence models in the application of HR instruments. For instance, to select new employees, to evaluate performance, to develop training and development plans or to build HR systems (Campion et al. 2011; Krumm et al. 2012; Mansfield 1996; McClelland 1998; Muff et al. 2020; Shippmann et al. 2000; Spencer and Spencer 1993).

Typically, competence models describe competences by considering their levels, for example a competence cluster, the competence description and observable behavior (Campion et al. 2011; Krumm et al. 2012; Spencer and Spencer 1993). Figure 2 shows how this structure is applied for the SPSM competence model.

\section{The methodological process}

\subsection{Competence model design approach}

In terms of the design of a competence model, the literature suggests the following systematic approach for deriving competences related to specific jobs or roles (Briscoe and Hall 1999; Dalton 1997; McClelland 1998; Spencer \& Spencer 1993). First, current and future challenges as well as performance criteria for the specific job area or position should be defined. Then, critical incident interviews should be conducted to gather successful and unsuccessful behavior, i.e. behavior experts see as either helpful in, or detrimental to, the successful resolution of the incident. Consequently, the documented interviews should be evaluated by conducting 
Fig. 2 Levels applied for the SPSM competence model (based on Campion et al. 2011, p. 240; Krumm et al. 2012, p. 1)
Competence cluster:

Competence name:

\section{Competence definition:}

Behavior:
Allocation of the competence in the chosen classification scheme

Label for the competence

\section{Describes how proficiency in the competence is revealed}

\author{
Observable behavior with \\ regard to the competence
}

a content analysis to gather the relevant competences that populate the competence model, including descriptions of behavior for each competence. Then, the newly developed competence model should be validated in practice (Dalton 1997). Complementing this research-based approach, Campion et al. (2011) defined three main steps as best practice in competence modelling: 'analyzing competence information (identifying competences)', 'organizing and presenting competence information', and 'using competence information' (Campion et al. 2011). This research has used the systematic approach described above for the design of the SPSM competence model as described in Sect. 3. With its broad focus on competences rather than on narrow job descriptions, the SPSM competence model development was undertaken using a systematic research-based approach, resulting in a versatile, multiple-job type of model.

Literature in the field of HR, in personnel or in organizational psychology provides a broad range of competence classifications (Bartram et al. 2002; Boyatzis 1982; Katz 1974; Mintzberg 1973; Nonaka and Takeuchi 1995; Smith 2002). Delamare Le-Deist and Winterton (2005), identified four types of competences which, although not situated within the PSM research area, provide an excellent framework for the design of the competence model in this research. In fact, this typology has been previously applied within the sustainability domain by Osagie et al. (2016) who investigated the competences required by CSR managers within organizations. The typology describes competences as being either cognition-oriented, functional-oriented, social-oriented, or meta-oriented. Cognition-oriented competences capture knowledge and understanding, skills are reflected in the functional-oriented competences and individual capabilities in the social-oriented competence cluster. Meta-oriented competences are "concerned with facilitating the other substantive competences" (Delamare Le-Deist and Winterton 2005, p. 39) and in this research this has been extended slightly to include personal attitudes and commitment. Table 1 summarizes the definitions for each competence cluster applied in this research.

\subsection{Identification of competences for the model}

In this sub section we discuss only the process steps that led to the SPSM competence model since more detailed discussions of the SLR and Delphi methods have already been published (Schulze et al. 2019; Schulze and Bals 2020). The research process that led to this competence model can be characterized as an inductive, exploratory approach, with

Table 1 Competence cluster definitions for SPSM competences, based on (Delamare Le-Deist and Winterton 2005)

Competence cluster Definition for the SPSM competence model

Functional-oriented competences

Cognition-oriented competences

Social-oriented competences

Meta-oriented competences
SPSM competences in a rather technical sense, directly related to an occupational context

SPSM competences that encompass generic knowledge and understanding related to a conceptual and systematic way of thinking

Competences how to interact with others, including willingness and ability to experience and shape relationships to foster SPSM

Competences that on a personal level facilitate the acquisition and application of the other substantive competences, sometimes positioned at the intersection between attitude and competence 
the aim of gathering qualitative data in what is a rather new research area. The researchers decided to follow a consolidated approach for quality assurance, with the aim of providing information to the audience based on quality criteria that reflect the qualitative, explorative character of the research project and its interpretive paradigm. At the same time, the criteria provided valid information about the value and generalizability of the findings. Therefore, traditional criteria for quality assurance were combined with others dedicated to qualitative research. The quality assurance was performed to address four main criteria, throughout the research process i.e. to ensure validity, reliability, confirmability/objectivity, and transferability (please see Appendix A).

Figure 3 outlines how the multimethod approach contributed to the development of the SPSM competence model.

As a first step, a systematic literature review (SLR) of work relating to SPSM competences from the extant body of literature was undertaken to provide a foundation for initial competence identification. From this SLR it was established that there is a substantial body of knowledge relating to supply chain competences (Flöthmann et al. 2018; Hohenstein et al. 2014) and in particular to those PSM competences required for what might be considered 'traditional' (e.g. cost or delivery) aspects of PSM (Giunipero et al. 2006; Giunipero and Pearcy 2000). However, in terms of the competences required to manage sustainability aspects of PSM, the SLR confirmed the SPSM competences to be considerably less well established. Furthermore, it has been recently suggested that this is an essential area for further research (Knight et al. 2019).

The SLR provided an initial set of competences and allowed for the identification of critical incidents (step 2) through which the competences could be explored by a set of subject experts using a Delphi Study design forming steps 3 and 4 of the model development process. Finally, in step 5 the competences were consolidated into the model and this is the work that is presented in this paper.

The SPSM Competence Model development process is now described in more detail.

\subsection{The initial SLR}

The results of the SLR (step 1 in Fig. 3) determined the current state of research coverage of SPSM competences, and therefore laid the foundation for the next steps in the model development. At the same time, the SLR led to the first preliminary set of competences. The SLR followed a structured process including: the definition and testing of search terms that were derived from the primary research question; the literature search and selection; the coding and analysis followed by the reporting of the results (Durach et al. 2017; Tranfield et al. 2003). The SLR began with a search using the keywords 'sustainability', 'competences and knowledge' and 'purchasing and supply management' and was conducted in September 2016 and then again in February 2019, using the Web of Science and EBSCO databases. This initial search returned a low number of papers and so was widened by removing restrictions on publication date and journal. A filtering process excluded papers with a nonrelevant subject matter, which used keywords as synonyms for other, non-relevant, terms, or which addressed organizational rather than individual level competences. A total of 22 papers were identified by this process as relevant to this research.
Fig. 3 Development of competence model

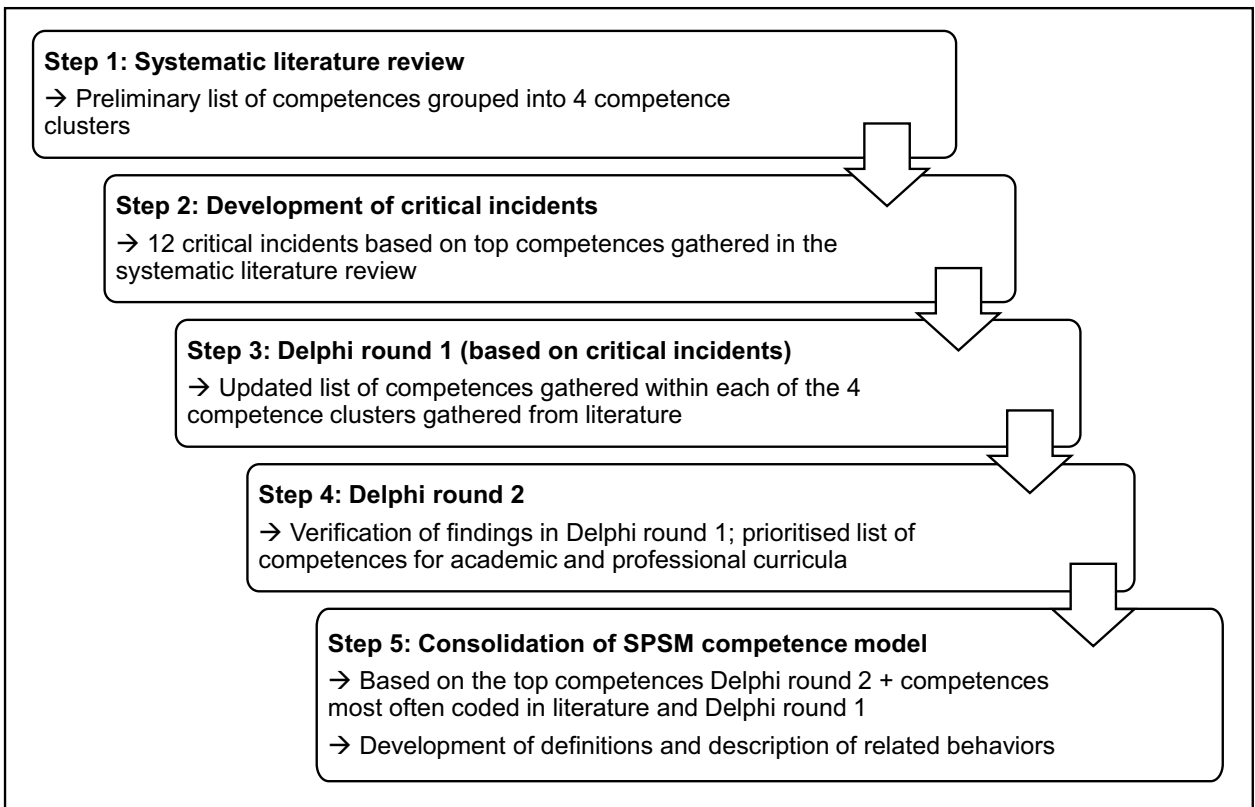


These remaining papers were coded (using NVIVO 11), based on the idea that PSM professionals need to embed sustainability into their daily professional practice and therefor the coding scheme was structured around the main tasks of a typical procurement process, including the strategic sourceto-contract scope as well as the transactional purchase-topay tasks (see Fig. 1). The coding process also unearthed additional competences which seemed independent of the daily functional and process tasks of the PSM professional (such as 'Systems thinking competence' or Cross-functional team working').

The SLR resulted in a first overview of competences required for SPSM consisting of 29 competences in all four domains according to the typology by Delamare Le-Deist and Winterton (2005). All the identified competences related to strategic PSM processes rather than transactional PSM process steps. The identified competences are shown in the second column in Table 2.

\subsubsection{From the SLR to the Delphi study}

In the second step, the results of the SLR led to the critical incidents (CI). The researchers selected the Critical Incident Technique (CIT) (Bartsch and Specht 2009; Brannicket al. 2012; Flanagan 1954) for three main reasons. First, they looked for a possibility to discuss competences in a way that made it convenient and engaging for the Delphi experts. For example, if simply being asked for a list of competences that they consider to be important for SPSM, the outcome would have probably been rather abstract, tedious and restricted. Second, the application of the CIT allowed the findings from the SLR to be adapted to the professional SPSM context and its current and future challenges. Moreover, the discussion of competences based on critical incidents was at the same time a structured but also explorative approach. Third, the CIT provided the Delphi experts with the opportunity to speak about situations that they were familiar with, and thus invited them to elaborate how these situations were handled based on their professional experience. In essence, CIT makes use of subject experts who are able to describe the actions and behaviors which allow critical incidents to be successfully dealt with and, conversely, the actions and behaviors that hinder success. A thorough discussion of the application of the Delphi method can be found in Häder (2014) and Linstone and Turoff (2011). Based on the subject experts' responses to the CIs, behaviors and actions are combined into clusters and dimensions from which competences can begin to emerge.

The CIs that were used in the Delphi study covered situations of high significance for SPSM, following the definition of a critical incident by Flanagan (1954). In using predefined CIs, this research followed Schuler (2014), who suggests that the dimensions of CIs might either be predefined, generated by statistical methods, or by expert consensus (Schuler 2014). The CIs in this study were derived from the most prominent competences and knowledge areas identified in the SLR thus indicating that these competences were critical from the research experts' point of view. The coding for each competence found in the literature, documented in NVivo 11, delivered descriptions of actions and behavior. Based on these descriptions, 12 CIs were derived, and elaborated based on examples taken from academic papers, text books, business press and publicly available case studies (see Appendix B). The CIs were then applied in the expert interviews in the first round of a Delphi study, being step 3 in Fig. 3. All experts confirmed that the 12 CIs represented an appropriate and broad set of issues to be addressed in the SPSM context. Additionally, to avoid confirmation bias, experts were provided with the opportunity to define their own CIs or to skip those incidents that they could not relate to.

The Delphi method in this research was structured using two Delphi rounds to gather input from 16 experts in the field of sustainability and PSM. The group of experts used were recruited from private companies and from public institutions (representing the professional face of SPSM) as well as experts from academia (responsible for producing the SPSM professionals of the future). Experts selected from the private sector worked in firms that publicly committed to SPSM and that was taken as evidence of efforts to implement SPSM. Also, the companies belonged to industries faced with considerable sustainability risk (e.g. chemicals, automotive). The experts had subject knowledge in PSM and sustainability. Experts from public institutions were included as public procurement is at the forefront of SPSM, due to laws and regulations (e.g. the modern slavery act in the UK). The educationalists included were expected to hold a chair either in sustainability management or purchasing management with a dedicated focus on sustainability and ethical issues.

The 16 experts described successful and unsuccessful behavior shown by PSM professionals in the CIs. The inclusion of both perspectives - successful and unsuccessful behaviors - provided a rich source of descriptions. Each interview took two hours. The descriptions were documented and then coded, following the same approach as with the academic literature in the SLR. The coding of the interview data complemented existing nodes, but also led to new ones. Additionally, during the process, some nodes were renamed or new sub-categories were built. This was driven by the richness of the data that was gathered. The data led to more precise and profound descriptions for each node or competence, and in turn therefore required adaptions in terms of the denomination or the grouping of codes to nodes. Overall, the evaluation and systematic coding of the transcribed interviews with Delphi experts, resulted 


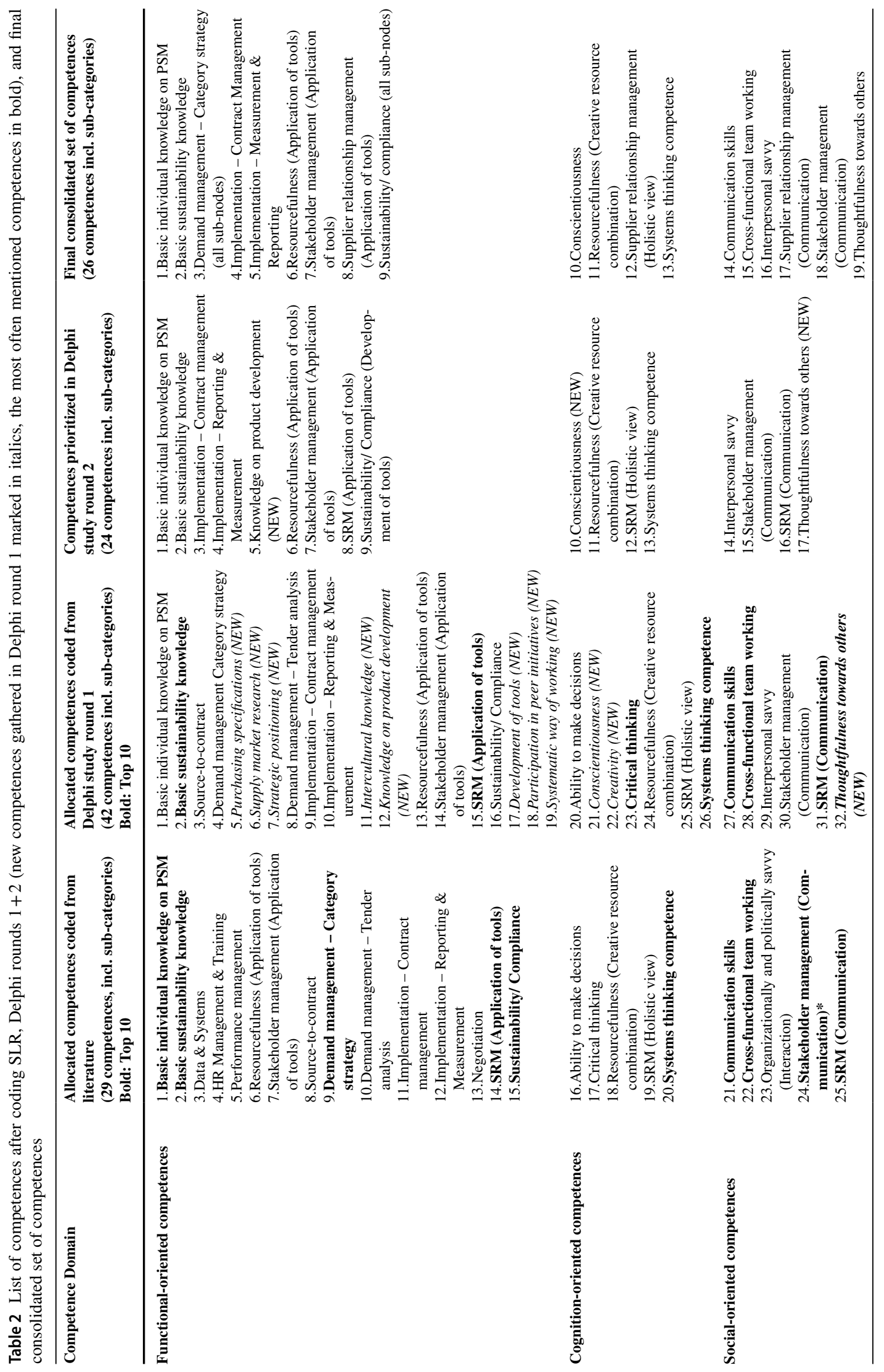




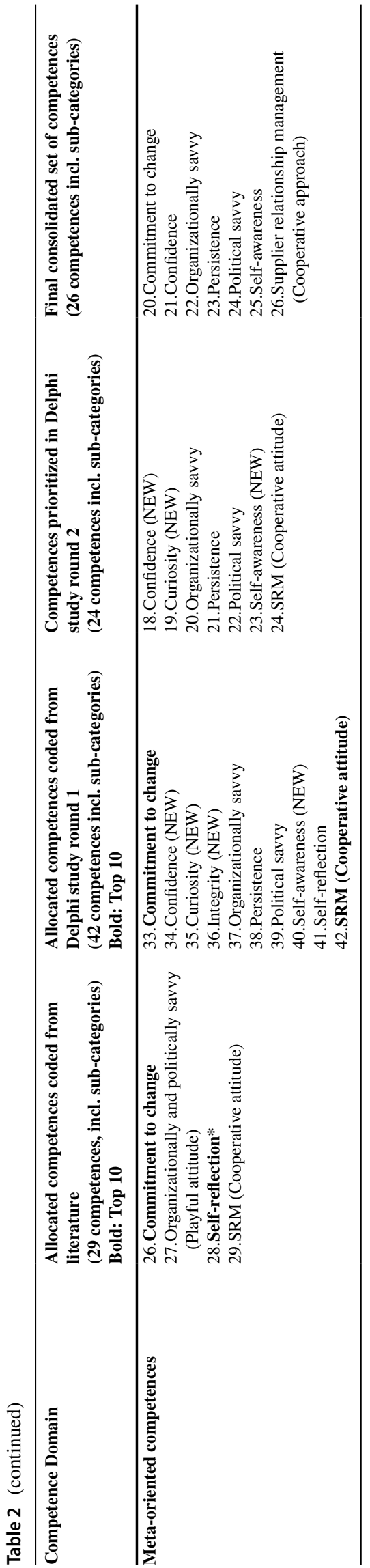

in an additional 15 nodes, and confirmed 27 of the nodes that were in the pre-defined set of the SLR. Table 2 lists all coded competences resulting from the SLR and both Delphi rounds, the latter highlighted with "NEW", as well as the final set of competences that was derived from the process.

After coding the interviews with the Delphi experts, 42 competences were identified. All of those were discussed and prioritized in step 4, the second Delphi round. In this step, the same group of experts prioritized 24 competences and, although given the opportunity, they did not add any additional competences that they considered missing in the list resulting from the first Delphi round. Overall, the evaluation of the literature resulted in a set of competences that was confirmed by Delphi experts. Even when considering the bias that the CIs were derived from the SLR findings, the experts were provided with the opportunity to add their own additional situations and actions in the interviews and in the second Delphi round. They were also free to reject given CIs if they felt they were not appropriate for their individual context. This included the opportunity to look forward to the inclusion of competences that may be desirable as sustainability issues emerge and roles evolve in the future.

The combination of the SLR and Delphi study provided a rich source of qualitative data describing SPSM competences and consolidation in step 5 of the process produced the final column in Table 2, where the set of 26 competences is shown. The consolidation process was based on consideration of four parameters. First, the final list was to include competences that were highly ranked throughout the entire research process. Second, complementing the first selection criteria, the final list should reflect competences that were related to PSM process steps. Third, the newly created competences gathered in the Delphi study should be reflected in the final set. Finally, to make the set as meaningful as possible, overlaps were avoided (for more details, please see Appendix C).

\subsection{Developing the competence model}

The previous section has outlined the process used to derive the final set of SPSM competences before model consolidation in step 5 of Fig. 3. As was mentioned earlier, a competence model should be more than just a list of competences albeit grouped into competence domains. Following the best practice suggestion of Campion et al. (2011) that there are three main steps in competence modelling, 'analyzing competence information (identifying competences)' was achieved through the use of the SLR and Delphi study, 'organizing and presenting competence information' is the model development and description that is presented in this paper, and 'using competence information' is further discussed in Sect. 5 below and should be the subject of further work linking to validation of the competence model. 
In 'organizing and presenting competence information' the identified competences were to be further described by linking each competence to a definition of the competence and to descriptions of behavior identified for each competence (Dalton 1997).

The qualitative information provided by the SLR and the Delphi study allowed a definition to be developed for each competence. Descriptions of successful behavior for each competence, taken from either the literature or the Delphi interviews, complemented the definition. For this purpose, the described positive and negative behaviors collected during Delphi round 1 were consolidated and summarized for each of the 26 competences. The negative behaviors allowed the clear identification of associated positive behaviors. Considering that most of the competences listed in the final set are rather general in terms of their denomination, the definition and in particular the behavioral descriptions are the core of the SPSM competence model. All of these SPSM competences, with a definition and related behaviors, are shown in Apppendices D-F and will be discussed in the following sub sections.

Definitions and descriptions, together with the critical incident situations, allow positioning of a competence in the SPSM context and process, and derivation, for example, of job descriptions or learning goals for SPSM training and education. It was decided not to specify any scales or levels of competence maturity, because the SPSM competence model was designed to provide a rather versatile framework that allows and requires adaptation to a specific organizational context. Companies need to tailor the SPSM competence model to strategic goals, to company culture, job roles and HR processes (Campion et al. 2011; Krumm et al. 2012; Mansfield 1996; Spencer and Spencer 1993). In the higher education context, educational institutions probably want to adapt and further elaborate the model to learning objectives and taxonomies in their study programs, their degrees and their curricula.

\section{The SPSM competence model}

The 5 steps to develop the competence model as outlined in Fig. 3 led to a set of 26 competences. Table 3 lists the competences by name and by competence cluster and is taken from the final column of Table 2 .

\subsection{Functional-oriented SPSM competences}

The functional-oriented competence cluster includes SPSM competences in a rather technical sense, directly related to an
Table 3 Final set of 26 SPSM competences
Functional-oriented competences

Cognition-oriented competences

Social-oriented competences

Meta-oriented competences

\author{
Basic individual knowledge on PSM \\ Basic sustainability knowledge \\ Demand management - Category strategy (all sub-nodes) \\ Purchasing specifications \\ Supply market research \\ Strategic positioning \\ Implementation - Contract Management \\ Implementation - Measurement \& Reporting \\ Resourcefulness (Application of tools) \\ Stakeholder management (Application of tools) \\ Supplier relationship management (Application of tools) \\ Sustainability/ compliance (all sub-nodes) \\ Development of tools \\ Participation in peer initiatives \\ Conscientiousness \\ Resourcefulness (Creative resource combination) \\ Supplier relationship management (Holistic view) \\ Systems thinking competence \\ Communication skills \\ Cross-functional team working \\ Interpersonal savvy \\ Supplier relationship management (Communication) \\ Stakeholder management (Communication) \\ Thoughtfulness towards others \\ Commitment to change \\ Confidence \\ Organizationally savvy \\ Persistence \\ Political savvy \\ Self-awareness \\ Supplier relationship management (Cooperative approach)
}


occupational context. Overall, the functional-oriented competence cluster is the one that includes the highest number of SPSM competences. The list of competences associated with this cluster, their definitions and observable behavior can be found in Appendix D.

All competences that describe specific elements of the PSM process (Fig. 1) were added to this cluster, as they refer to PSM activities that need to be performed in an operational sense. 'Demand management - Category strategy', including the sub-nodes 'Purchasing specifications', 'Supply market research' and 'Strategic positioning', 'Implementation Contract management' and 'Implementation - Measurement \& Reporting' refer to the source-to-contract part of a PSM process. 'Supplier relationship management (Application of tools)' and 'Sustainability/ compliance' with its sub-nodes 'Development of tools' and 'Participation in peer initiatives' belong to the level of competence centers. Supplier relationship management is the only process-driven competence that is also included in the other competence clusters, depending on a focus on tool application, communication, holistic view or cooperative approach.

'Basic individual knowledge on PSM', 'Basic sustainability knowledge', and 'Resourcefulness (Application of tools)' can be considered as fundamental competences that are not related to specific elements of the PSM process but are required for all process steps and roles in SPSM. Therefore, especially when looking at the descriptions of behavior for 'Basic individual knowledge on PSM', interrelations can be seen to 'Category strategy - Demand management', to 'Implementation - Contract management', and to 'Implementation - Measurement \& Reporting'. Another rather generic competence is 'Stakeholder management (Application of tools)'. As it excludes suppliers from the stakeholder understanding, which are covered in the competence 'Supplier relationship management (Application of tools)', it is suggested to be an underlying competence for 'Sustainability/compliance', assuming that dealing with all kinds of stakeholders outside the supplier relationship is probably part of the job role in a competence center rather than of a job role in the source-to-contract process.

\subsection{Cognition-oriented SPSM competences}

Cognition-oriented SPSM competences are types of conceptual competences in an occupational context. They encompass generic knowledge and understanding related to a conceptual and a systematic way of thinking. The list of competences associated with this cluster, their definitions and observable behavior can be found in Appendix E.

The cognition-oriented area, 'Supplier relationship management (Holistic view)' reflects the cognitive and intellectual competence to understand the broader context of
SRM, compared to the functional character of SRM that covers the operational ability to apply tools. Therefore, the authors found this competence to fit with the cluster definition for the cognition-oriented area. It includes, for instance, the understanding of a supplier's motivation, and the ability to find solutions that benefit both sides in a buyer-supplier relationship. 'Systems thinking competence' is closely connected to this aspect of supplier relationship management, but with a broader view on the supply chain network. Literature and Delphi expert interviews mentioned 'Systems thinking competence' as one of the most important SPSM competences. It includes the understanding of interdependencies within members in a supply network and the recognition of the impact of SPSM measures in terms of risk and opportunities. New approaches such as circular economy concepts foster and require 'Systems thinking competence' for SPSM, for instance, to understand process requirements as well as financial impacts on the involved parties. As of the Delphi experts, purchasing professionals who are competent in 'Systems thinking' can describe a business case for sustainability, and consider the view of different stakeholders. Based on these examples and descriptions which include a conceptual and an occupational aspect, 'Systems thinking competence' was assigned to the cognition-oriented domain.

'Conscientiousness' is the third competence in the domain here. It was defined as the ability to thoroughly analyze SPSM issues combined with a manner of carefully approaching solutions and taking issues and situations seriously. The allocation of 'Conscientiousness' in the cognitionoriented cluster is arguably not clear at first sight when thinking about what it means to carefully deal with a situation or to take an issue seriously. It might also fit to the social- or meta-oriented competence cluster. But the descriptions of observable behavior clearly led to the decision to allocate 'Conscientiousness' in the cognition-oriented cluster. The descriptions all included a notion of thinking something through before acting in an occupational context, of the ability to gather an understanding, and to thoroughly investigate on SPSM issues in a conceptual and systematic way. In this regard, 'Conscientiousness' may also be a supporting competence for 'Systems thinking competence', and also for'Supplier relationship management (Holistic view)'. Finally, compared to the latter two competences, 'Resourcefulness (Creative resource combination)' is a cognitive competence on a more operative occupational level. As it can be seen in the descriptions for this competence in Appendix E, the core characteristic can be summarized as being efficient and effective when dealing with SPSM issues in the occupational context. Compared to 'Resourcefulness (Application of tools)' within the functional-oriented competence cluster, the specification here is concerned with conceptual methods and a systematic way of working. Considering that 
SPSM is a task that purchasing professionals need to cope with in addition to their daily job (Fayezi et al. 2018; Goebel et al. 2018), 'Resourcefulness (Creative resource combination)' might be a competence that contributes to successfully implement SPSM in all steps of the PSM process and the job roles that are involved.

\subsection{Social-oriented SPSM competences}

Social-oriented competences enable the interaction with others to cope with sustainability issues, including the willingness and ability to experience and shape relationships to foster SPSM. The list of competences associated with this cluster, their definitions and observable behavior can be found in Appendix F.

Some aspects of communication are captured by the competence 'Communication skills', including the ability to articulate and present sustainability issues in a convincing manner by applying appropriate communication styles and channels depending on target groups and situations.

However, as the SLR and the Delphi study resulted in a range of different behavioral descriptions around communication competence, it was decided for the SPSM competence model not to subsume the descriptions to one general communication competence like 'Communication skills', but to add other more specific categories. Therefore, SRM is also included here. Whereas the functional aspect of SRM is covered in the application of SPSM tools and therefore part of the functional-oriented competence cluster, the cognitive aspect is around the understanding and awareness of the supplier point of view. 'Supplier relationship management (Communication)' is the personal competence to interact with suppliers in such a way to achieve SPSM goals. 'Stakeholder management (Communication)' is comparable in its character, but addresses other stakeholders than suppliers, whereas 'Cross-functional teamworking' encompasses the interaction with the internal interfaces within an organization to foster SPSM.

Besides the competences that deal with communication in the PSM context, two others were allocated in the socialoriented cluster: 'Thoughtfulness towards others' and 'Interpersonally savvy'. Being rather less explicit than the other competences in the cluster, both of them might be seen as enablers for interaction in the field of SPSM. 'Thoughtfulness towards others' includes a certain attitude when dealing with others, contributing, for instance, to a more cooperative, de-escalating communication style. To a certain degree, there is a close connection to 'Conscientiousness' in the cognition-oriented area, but 'Thoughtfulness towards others' stands by itself as aiming towards the interaction with others. Therefore, it was listed as a separate competence within the social cluster. Finally, including 'Interpersonally savvy' in the social-oriented competence set ensured that the importance of being able to relate to others personally and sometimes in an informal manner was sufficiently represented in the SPSM competence model.

When discussing the impact of the social-oriented competences on the PSM process steps, it became apparent that there are various interfaces. For example, 'Cross-functional teamworking' might be especially important for 'Demand management - Category strategy' when looking at the definition of this process step, which includes for example "Support internal customers in purchasing specifications; functional and technical" or "Build a category team with different non-purchasing functions". 'Stakeholder management (Communication)' is probably an asset for 'Sustainability/ compliance' (competence center). For both of those, different job descriptions are probably applicable.

\subsection{Meta-oriented SPSM competences}

Meta-oriented competences complement the cognitiveoriented cluster on the personal level. Following Delamare Le-Deist and Winterton (2005), meta-oriented competences facilitate the acquisition and application of the other substantive competences. Especially when applied in the SPSM context, meta-oriented competences are sometimes positioned at the intersection between attitude and competence. The list of competences associated with this cluster, their definitions and observable behavior can be found in Appendix D.

The twofold character of competences in this field of being a competence and/or an attitude is, in particular, relevant for 'Commitment to change' which is defined as the individual motivation to implement sustainability in PSM, and to be open and willing to change routines. When looking at the descriptions for successful behavior, they include facets of passion, willingness and personal interest to get engaged in sustainability-related issues and to contribute to successful SPSM. Literature and Delphi experts gave 'Commitment to change' a top priority. Therefore, it was decided to include this aspect in the SPSM competence model as a meta-oriented competence, being aware of the difficulty to clearly differentiate between attitudes and competences. 'Confidence' is nearly similar in terms of its positioning between attitude and competence, and it includes the understanding of what needs to be done, and at the same time the courage to do what needs to be done. There is a significant relation to 'Persistence', emphasizing the competence and the attitude to follow-up closely and not let go when dealing with SPSM. Both 'Confidence' and 'Persistence' are enablers for the acquisition of other SPSM competences and were therefore assigned to the meta-oriented cluster. 'Organizationally savvy' and 'Politically savvy' are types of wisdom or intelligence, adding to the 'Interpersonally 
savvy' competence in the social-oriented field. Contrary to the communicative stance of the latter, these two encompass the understanding of organizational mechanisms ('Organizationally savvy'), and the usage of a repertoire of politics in an organization ('Politically savvy'). Without doubt, the three competences are closely related. Literature and Delphi experts emphasized all of them, pointing out that they become especially relevant when the organizational enabling for SPSM is not very mature. Finally, 'Self-awareness' was added to the meta-oriented cluster, being at a certain level the match to 'Conscientiousness' in the cognitive area, focusing on the intrapersonal aspect.

All meta-oriented competences foster SPSM in any of the PSM process steps and functions and job roles that are implied. 'Supplier relationship management (Cooperative attitude)' was added as a separate category also in this competence cluster. It was decided to add the attitudinal character of this competence even in its title, because the competence is focused on the motivation and understanding of SRM and is clearly a facilitator for the other three forms of SRM that are reflected in the SPSM competence model.

\section{Conclusions: implications, limitations and future research}

This study aimed to fill the gap in research on individual sustainability competences required for SPSM. The main focus was on both the social and environmental aspects of sustainability. The study looked for answers to the leading research question "Which individual competences of PSM professionals are required to implement SPSM?" A multimethod approach that combined a systematic review of academic literature on sustainability competences with the findings from a Delphi study led to a set of 26 SPSM competences, defined and denominated in a SPSM competence model. The multimethod approach allowed identification of the set of 26 SPSM competences, although limitations need to be acknowledged. In brief, the SLR was a one-time screening of a pre-defined sample set using the Web of Science and EBSCO databases. Having conducted the SLR in 2016, there might have been other papers published in the meantime related to the research question. In order to check for this, the database was revisited in the first quarter of 2019, but nevertheless it cannot be completely ruled out that some recent publications might have been missed (e.g. still under review at that time). Also, the Delphi study is based on the restricted number of 16 experts. A discussion of the results with a broader set of experts or, for example, approaching the analysis with an in-depth case study might be valuable next steps. For further validation, a follow-up study covering all 26 competences and including a larger data set for empirical testing is recommended. Herein, it would be interesting to differentiate between academic and corporate settings, as well as public and private for the latter. Having listed these limitations, our study provides answers to our research question though, and contributes to filling the identified research gap, while at the same time offering a range of further research opportunities.

As outlined earlier, following the model by Von Rosenstiel (Von Rosenstiel 2011; Von Rosenstiel and Koch 2003) SPSM implementation is influenced both by organizational and individual factors.

In what follows, we analyze the impact and discuss our findings in light of this model.

\subsection{Implications}

For research on SPSM from an organizational point of view in particular, the analysis of the relevance of competences with regard to purchasing process stages (Fig. 1) offers a conceptual basis for bringing sustainability into overall PSM models, instead of simply positioning sustainability as an 'add-on' activity, which risks the potential of sustainability issues becoming marginalized. This follows the suggested perspective of Johnsen et al. (2014) that sustainability should be consistently embedded into all PSM processes. This perspective is also in line with Aguinis and Glavas (2013), who distinguished on a general organizational level between embedded and peripheral CSR.

For research on SPSM from an individual view, being one of the first studies on the nature of SPSM competences for individual purchasing professionals, this paper adds the sustainability perspective, focusing on both the social and environmental aspects of sustainability, to complement existing research on individual PSM and SCM competences (Flöthmann et al. 2018; Giunipero et al. 2006; Giunipero and Pearcy 2000; Hoberg et al. 2020; Hohenstein et al. 2014). Besides a mere adding of SPSM competences to existing framework proposals, the nature of the SPSM competences that resulted from this study may drive a discussion in the academic field as to how SPSM competences are related to a future competence profile for PSM professionals. For example, when comparing the sustainability competences with the findings of Tassabehji and Moorhouse (2008), Giunipero and Pearcy (2000) or Bals et al. (2019), our competence model adds the sustainability perspective, but also the perspective on holistic supply chain management. With a broader view, for HR research in the context of sustainability related competences, our study also underlines the role of "conscientiousness", found to be a major factor in whether individuals engage in ethical behavior or not (Parks-Leduc et al. 2020). In this regard, it might be interesting to further compare studies on sustainability competences beyond 
the PSM scope. For example, Osagie et al. (2016) provide a list of competences for CSR managers, using the same competence clusters from Delamare-Le Deist and Winterton (2005). The comparison shows that the clusters from Delamare Le-Deist and Winterton (2005) provide a helpful framework to group competences in a model that allows differentiation between types of competences. A comparison of the identified competences in the work by Osagie et al. (2016) and other studies (Galleli and Hourneaux Junior 2019 2020; Lambrechts et al. 2013; Mochizuki and Fadeeva 2010; Wiek et al. 2011; Willard et al. 2010) may enrich the SPSM competence model provided in this study.

From a managerial perspective, this work contributes to the pertinent question of how PSM organizations and managers can foster sustainability throughout supply chains in practice by considering both, the organizational and the individual level. The introduced Rosenstiel model (Von Rosenstiel 2011) provides a framework for managerial decisions, as it highlights that organizations need to invest in both the organizational level and the individual level, i.e. select the right employees and train them. The former is essential, as it requires 'situational enabling' and 'empowerment $\&$ obligation' on the organizational level to have individual level SPSM competences contributing to a firm's sustainability performance (Von Rosenstiel 2011). Put differently, even the best individual SPSM competences will hardly come to fruition if there is no organizational frame in which to apply them. Therefore, organizations may take the SPSM competence model as a blueprint for the development of their specific SPSM competence model embedded in the respective organizational context. Being a versatile competence model, it provides the basis for implementation in a specific firm (Campion et al. 2011; Krumm et al. 2012; Mansfield 1996; Spencer and Spencer 1993). They should position it in the organizational strategic context, aligning it with strategic and operational goals, and finally translate it into a set of HR processes and tools, e.g. job descriptions, job roles and assessment methods (Campion et al. 2011; Krumm et al. 2012). On an individual level, as mentioned in the introduction, training for purchasing professionals should be an integral part of SPSM approaches in organizations (Villena 2019).

In order to further focus their efforts, for example, in hiring and training for SPSM competences, organizations may consider which SPSM competences are relevant for each phase in the PSM process as outlined in Fig. 1. As the results of this research indicate, some process elements require more SPSM competences than others. For instance, 'Category strategy', 'Supplier relationship management' and 'Sustainability/compliance' were identified as being relevant for SPSM. These results probably lead to the description of three main roles that are the most relevant for SPSM. First, a strategic sourcing professional, doing the category strategy. Second, a supplier manager, being responsible for the implementation and monitoring of SPSM performance criteria and supplier development. Third, a role that might be located in a center of competence or the staff department dealing with 'Sustainability/compliance' in terms of setting SPSM standards, supporting operative functions in their implementation and dealing with stakeholder relationships. Depending on the size and overall organization of a firm's PSM department, these roles might be separated or simply reflect different aspects of certain PSM positions. When looking at the list of SPSM competences that was developed in this research, 'Systems thinking competence' in the meaning of the ability to recognize interdependencies within a supply chain network may be especially relevant for professionals in the fields of 'Category strategy', 'Supplier relationship management' and 'Sustainability/compliance'. Companies may consider how to reflect this in their HR decisions for posts in these fields. For example, by hiring professionals with work experience in another stakeholder position.

\subsection{Future research suggestions}

First, as this research was centered on a multimethod approach combing several qualitative methods, more empirical studies applying different research strategies would be useful to further validate, evaluate and develop the SPSM competence model, also taking into consideration contingency factors like type of organization, its supply chain position, products/services being purchased and major sustainability risks within the respective industry and its supply chain. This could be done by a quantitative survey, or first by other qualitative research strategies, for example by conducting an extended Delphi study including more experts or running case studies or action research projects in organizations. Following the social-constructivist approach (Easterby-Smith et al. 2008), an even more in-depth involvement of the researcher in the data collection process, for example by observations in the field, is suggested. Recognizing that supplier relationship management was given a high priority in all four competence clusters in literature and from the experts in the Delphi study, it would be interesting to see more research that focusses on this aspect in the light of increasing sustainability expectations towards companies and their supply chain partners. For example, an extended Delphi study or action research might further investigate how supplier relationship management is linked to competences in the other competence clusters, like 'Systems thinking competence', 'Stakeholder management' or 'Persistence'. Taking into consideration the current issues 
in many supply chains in terms of delivery and availability of goods, it would be particularly interesting to see if these SPSM competences for supplier relationship management contradict the current challenges or, on the other hand, whether they contribute to their solution. Further studies could also look at other sources to gather SPSM competences like job advertisements for PSM professionals. Recent developments and legislation regarding circular economy and carbon neutrality might have an impact on expectations towards purchasing professionals and their technical knowledge and understanding when performing demand management, which can be reflected in job descriptions and recruitment strategies for PSM roles. Another interesting approach here could be the integration of a stakeholder point of view, asking suppliers or NGOs what they consider to be relevant SPSM competences.

Also, since this research largely framed the study in the context of a model from organizational psychology (Von
Rosenstiel 2011; Von Rosenstiel and Koch 2003), more research on the impact of individual competences on organizational SPSM capabilities would be interesting (Dzhengiz and Niesten 2020).

From an educational point of view, further work on innovative teaching and learning methods for SPSM competences in all four competence clusters is suggested, taking into consideration commonalities but also differences between the HE environment and the professional training context. The viewpoint here might even need to be enlarged when looking at sustainability performance of an entire supply chain, including sustainability training for suppliers (Villena 2019), or the integration of SPSM in curricula at business schools (Kolb et al. 2017). Developing individual SPSM competences through HE curricula and through professional in-house as well as supplier training programs then may hopefully pave the way to truly foster sustainability throughout supply chains.

\section{Appendix A: SPSM competence model development - overview quality assurance (adapted from Lincoln and Guba 1985; Maxwell 1997; Mayring 1993; Sinkovics et al. 2005; Strauss and Corbin 1994)}

\begin{tabular}{|c|c|c|c|}
\hline Validity & Reliability & Confirmability/ Objectivity & Transferability \\
\hline $\begin{array}{l}\text {-Multimethod approach: } \\
\text { Applying different research } \\
\text { methods to gather findings; } \\
\text { Inter-connect the findings of } \\
\text { each method to the others } \\
\text { applied in a later stage of the } \\
\text { research process }\end{array}$ & $\begin{array}{l}\text {-Detailed description about the } \\
\text { decisions and how conclusions } \\
\text { were drawn in the research } \\
\text { process } \\
\text {-Discuss research approach and } \\
\text { findings with peers }\end{array}$ & $\begin{array}{l}\text {-Systematic and rigorous research } \\
\text { approach }\end{array}$ & $\begin{array}{l}\text {-Extraction of categories and } \\
\text { clusters that are applicable in } \\
\text { other contexts than the research } \\
\text { participants }\end{array}$ \\
\hline $\begin{array}{l}\text {-Communicative validation of } \\
\text { research findings: Member } \\
\text { checks; peer-reviewed } \\
\text { publication of research results }\end{array}$ & $\begin{array}{l}\text {-Pre-tests and codings with } \\
\text { multiple raters }\end{array}$ & $\begin{array}{l}\text { - Transparency in describing } \\
\text { how decisions were taken and } \\
\text { conclusions were drawn } \\
\text { - Researcher was familiar with the } \\
\text { research phenomenon based on } \\
\text { her academic and professional } \\
\text { expertise }\end{array}$ & $\begin{array}{l}\text {-Evaluation of findings in the filed } \\
\text { by applying action research in } \\
\text { different settings } \\
\text { - Discuss results with peers and } \\
\text { with research participants to } \\
\text { ensure terms and descriptions are } \\
\text { intelligible }\end{array}$ \\
\hline $\begin{array}{l}\text {-Evaluation of results based on } \\
\text { research question and defined } \\
\text { coding approach }\end{array}$ & & $\begin{array}{l}\text {-Cross-reference of the findings } \\
\text { resulting from the different } \\
\text { research methods }\end{array}$ & \\
\hline
\end{tabular}




\section{Appendix B: critical incident sources}

\begin{tabular}{ll}
\hline $\begin{array}{l}\text { Critical Incident } \\
\text { Number }\end{array}$ & Source \\
\hline 1 & Johnsen et al. 2014, pp. 48-51 \\
2 & Johnsen et al. 2014, pp. 86-89 \\
3 & Busse et al. 2016, pp. 442-468 \\
4 & Schneider and Wallenburg 2012, pp. 243-257 \\
5 & Rahbek and Pedersen 2015, pp. 60-65 \\
6 & Hofmann et al. 2015, pp. 115-141 \\
7 & Zadek 2004, p. 129 \\
8 & Johnsen et al. 2014, pp. 158-160 \\
9 & The Case Centre 2017 \\
10 & Zadek 2004, p. 129 \\
11 & Rahbek and Pedersen 2015, pp. 60-65 \\
12 & Rahbek and Pedersen 2015, p. 276 \\
\hline
\end{tabular}

\section{Appendix C: details on consolidation of the competence set}

The entire list of 24 competences prioritized in Delphi round 2 was taken for the final set, with two exceptions being made. First, the codings for 'Curiosity', for example "Is eager to learn" or "Is open towards challenges", led to the decision to merge 'Curiosity' with 'Commitment to change'. Second, 'Knowledge on product development' was assigned to 'Demand management - Category strategy'. This was decided because the gathered descriptions of behavior provided evidence of these two competences being closely connected. For example, for 'Demand management - Category strategy' it was coded "[...] talks to the product development department to understand what materials are not allowed", and very similar for 'Knowledge on product development': "Understands the interconnection of product development, raw materials and risk". Then, priority competences from the SLR and the first Delphi round were added to the list, covering 'Demand management - Category strategy' with all sub-nodes, 'Sustainability/compliance' with all sub-nodes, 'Cross-functional teamworking', 'Communication skills' and 'Commitment to change'. Two competences that were part of the top 12 or top 10 in the SLR and in Delphi round 1 were not taken for the final list, namely 'Self-reflection' and 'Critical thinking'. For 'Self-reflection' it turned out that the node 'Selfawareness' which was newly created based on the Delphi expert input, covered in a more comprehensive manner a comparable range of behavior. For instance, "Is aware and conscious when she/he cannot answer some of the questions" was coded for 'Self-reflection', whereas "Is aware of own sphere of influence, competences and role" in a later stage led to 'Self-awareness'. Similarly, 'Critical thinking' was not taken over to the SPSM competence set. Although it was within the top 10 competences in the first Delphi round, experts did not prioritize 'Critical thinking' in the second round. Again, when looking at the codings, it turned out that other competences include what was coded earlier in the 'Critical thinking' node. For example, "Is able to keep to the topic; shows endurance in asking questions" was at a later stage in the process more appropriately covered in the node 'Persistence'. Finally, the authors checked whether competences that were newly created based on the expert interviews are represented in the final SPSM competence set. For four of them they decided not to include them: 'Creativity', 'Systematic way of working', 'Intercultural knowledge' and 'Integrity'. For 'Creativity' and 'Systematic way of working', the coded data did not support the creation of a rich SPSM competence. The latter is covered in a more specific relation to SPSM in the nodes 'Resourcefulness (Creative resource combination)', 'Resourcefulness (Application of tools)' and 'Conscientiousness'. For 'Creativity', the node included only eight codings, which were rather general, as for example "Is creative to find new solutions". With 'Integrity', the authors decided that 'Self-awareness' and 'Confidence' cover related items in a more applicable manner. For example, "Acts in a reliable way" or "Indicates that this does not meet her/his personal values" fit to the latter two. The decision to leave out 'Intercultural knowledge' is arguably to be discussed. In the process of this research, the codings for 'Intercultural knowledge' were redundant to 'Communication skills', 'Implementation-Contract management' and 'Supplier relationship management (Communication)'. Nevertheless, considering global supply networks, intercultural competence is apparently relevant. A further development of the SPSM competence set might evaluate whether the intercultural aspect should rather be an integral part of other competences, as it was decided at this stage, or if a separate competence category is needed 


\section{Appendix D: functional-oriented SPSM \\ competences}

\section{Functional-oriented SPSM competences}

\section{Competence name: Basic individual knowledge on PSM}

\section{Definition:}

Basic individual knowledge on PSM is the understanding of the role of the function, and the ability to contribute to this role in terms of the "[...]management of the company's external resources in such a way that the supply of all goods, services, capabilities and knowledge which are necessary for running, maintaining and managing the company's primary and support activities is secured at the most favourable conditions" (Van Weele 2014, p. 8)

Observable behavior (based on CIs)

-Is familiar with the purchasing strategy

-Knows the company processes

-Looks at process descriptions

-Looks at the materials database

-Knows the performance of the supply base (economically, ecologically, social)

-Analyzes the dependency of this supplier

-Conducts market analyses

-Investigates on potential suppliers

-Explains the sourcing situation (cost, sourcing capacity) to colleagues

-Knows and understands price developments

-Explains how prices could be kept (e.g. through bundling)

-Does a classic Pareto analysis

Competence name: Basic sustainability knowledge

\section{Definition:}

Basic sustainability knowledge includes a general sustainability subject matter expertise as well as

knowledge about laws, regulations and frameworks and specific rules and procedures within an

organization

Observable behavior (based on CIs)

$\bullet$ Knows generic trends in sustainability

-Knows a range of sustainability solutions related to products or processes

-Knows legislation

-Knows the mission and the sustainability strategy of the own company

-Knows the established compliance processes in the company

-Knows the thresholds of the organization

-Understands what non-compliance to environmental standards mean to the supplier, the own company and the other companies in the industry in terms of risk

-Is able to ask for specifics e.g. about environmental or social aspects within her/his commodity/category

-Knows about other organizations which provide useful sustainability information

-Knows and understands eco-balances

Competence name: Implementation - Contract management

Definition:

Contract management in the SPSM context requires the competence to incorporate the various dimensions of sustainability requirements into contracts with suppliers (Johnsen et al. 2014), and taking into consideration the requirements of the relevant legal system that a contract is based on, as well as the impact on PSM processes

Observable behavior (based on CIs)

-Is aware of legal implications if a sustainability dimension is integrated in contracts

- Understands how to include human rights and environmental standards in contracts

-Breaks down general guidance into specific requirements that can be integrated in certain process steps (e.g. contracts)

-Understands what is in the contract

-Does not impose the laws and standards of the own country to the suppliers' countries

Competence name: Implementation - Measurement \& Reporting

Definition:

Measurement \& Reporting in the SPSM context requires the competence to monitor, document and report suppliers' sustainability performance based on KPIs

Observable behavior (based on CIs)

-Proposes how to integrate sustainability in the supplier evaluation process

-Develops ideas how adherence to a code of conduct can be monitored with the existing supplier management processes and tools

-Discusses and derives targets for procurement

-Develops a standard reporting template and integrates supplier data to get an overview how every supplier complies with the code of conduct

-Works to get approval for changing the KPIs and performance metrics

-Keeps a file with complete information in which suppliers signed the code of conduct, and copies of them

-Sets up regular meetings with suppliers to monitor measures

Competence name: Demand management - Category strategy (Purchasing specifications; Supply market research; Strategic positioning) 


\section{Functional-oriented SPSM competences}

\section{Definition:}

"Category management is the process of developing insights into stakeholder requirements, comparing these to external industry intelligence, supply base capabilities and operational risks, and developing a strategy to align internal requirements with external supply market conditions" (Monczka et al. 2016, p. 47). For SPSM, it includes the competence to gather and understand purchase needs specifications in terms of their sustainability impact, to search the supply market for sustainable products or solutions, and to derive a strategic approach how to include sustainability in the processes of category management

Observable behavior (based on CIs)

-Tries to get informed by talking to the product development department to understand what materials are not allowed

-Looks out for substitutes and discusses with subject matter experts

-Explores other more sustainable sources

-Has insights in the market of commodities (e.g. raw materials)

- Reflects if a certain component fits to the strategic long-term purchasing and product portfolio from a sustainability point of view

-Explains how the company can benefit from suppliers in terms of its sustainability strategy

-Explains the consequences of changes for the sourcing of any kind of material

-Takes a look at the goals of the company and thinks of how purchasing could contribute (e.g. reduce the carbon footprint by working together with suppliers on this issue)

\section{Competence name: Resourcefulness (Applications of tools)}

\section{Definition:}

Resourcefulness in the sense of tool application is the competence to apply existing SPSM standards and tools provided by external parties, either based on own

knowledge or by using external know-how and resources

Observable behavior (based on CIs)

- Conducts online research and gets an appropriate set of standard documents that can be applied

-Looks at code of conducts of peer companies

-Looks at industry standards

-Applies industry standards

-Buys external know-how if required

-Consults with specialists including external organizations and NGOs

\section{Competence name: Stakeholder management (Application of tools)}

\section{Definition:}

Stakeholder management can be defined as "Assessing the interests and impact on influencing parties on purchasing decision-making outcomes" (Van Weele 2014, p. 34), here applied to the SPSM context. It includes being able to identify stakeholders and to assess their interests, and to implement a range of different working models, adapted to specific stakeholder groups*

* Excluding suppliers, as this is covered in Supplier relationship management (Application of tools) in

this model

\section{Observable behavior (based on CIs)}

-Looks out for stakeholders in this procedure like the marketing department in the own company, government, other customers

- Tries to assess and determine what are the goals and plans of the stakeholders

-Develops a cooperation and integration strategy with NGOs

-Involves a third party perspective (e.g. NGO)

-Works together with all parties involved

- Offers different approaches to the stakeholders to achieve the goals

Competence name: Supplier relationship management (Application of tools)

\section{Definition:}

Supplier relationship management (Application of tools) is the competence to be aware of a range of tools to be applied in the SPSM context. In includes the ability to choose the best tools and make use of them in a specific situation

\section{Observable behavior (based on CIs)}

-Looks at the existing supply base and ranks suppliers on a sustainability scale

-Looks at potential environmental and social risks of potential suppliers

-Thinks of how to monitor (e.g. by auditing with internal or external auditors)

-Evaluates suppliers based on a code of conduct

-Asks suppliers for what the company wants in terms of data and information

- Meets with the supply base to go through the code of conduct and the measures that have been taken

-Asks for certificates and data from suppliers

-Asks for policy on ethical buying and selling

-Asks for proof and examples (e.g. personnel records)

-Conducts pre-qualification training for suppliers

-Applies a self-assessment questionnaire

-Develops an action plan with the supplier to implement the guidelines

-Applies audits on a case-by-case decision

-Prepares for how to ask questions during the audit

- Has an escalation process in place

-Anounces purchase stops 


\section{Functional-oriented SPSM competences}

Competence name: Sustainability/compliance (Development of tools; Participation in peer initiatives)

Definition:

The competence required in a center of excellence for sustainability/compliance is to develop a SPSM strategy and to derive concepts and measures for its imple-

mentation internally in the organization as well as with various external stakeholders

Observable behavior (based on CIs)

-Defines for the organization "What is sustainability for us?"

-Formulates minimum standards as a first step in case there is nothing yet, and then starts with monitoring measures and other activities

-Links the approach to industry initiatives

-Participates in industry initiatives or initiates participation of the own company

-Develops a code of conduct

- Considers regulations in the context of a code of conduct

-Sets up rules/a zero-tolerance definition under which certain suppliers should not be nominated/be given business

-Establishes a process how to react if a supplier does not sign the code of conduct

-Evaluates appropriate ways for direct monitoring

-Develops a questionnaire for suppliers

\section{Appendix E: cognition-oriented SPSM competences}

\section{Cognition-oriented SPSM competences}

\section{Competence name: Conscientiousness}

\section{Definition:}

Conscientiousness is defined as the ability to systematically gather facts before taking a decision, to understand details and a broader context of a sustainability issue at the same time. This analytic ability is combined with a manner of approaching solutions carefully and taking issues and situations seriously

Opposite: Jumping to conclusions and looking for fast solutions

Observable behavior (based on CIs)

-Is very careful with jumping to conclusions

-Investigates thoroughly on the topic

- Tries to get to the bottom of the issue

-Sorts out the situation/clarifies the issue

-Balances possible directions/solutions

-Takes her/his time to avoid mistakes

-Analyzes the situation

-Follows up carefully

-Takes care of follow-up activities personally and does not delegate them

-Goes to the supply market only when specifications and regulation requirements are clear

-Proceeds step by step

-Makes an effort to follow the audit report properly

Competence name: Resourcefulness (Creative resource combination)

Definition:

Resourcefulness in the meaning of creative resource combination is the competence to systematically implement SPSM aspects efficiently and effectively in a given environment, taking into consideration financial or other resource restrictions. It includes the ability to develop concepts and to find solutions based on existing procedures and processes for SPSM, as well as the capability to evaluate and combine different resources in favour of SPSM goals

Observable behavior (based on CIs)

-Focuses on priorities to start with

-Makes a proposal how sustainability could be integrated in existing processes

-Defines a threshold for process integration

-Uses solutions that are already there that suit the need of the company

-Understands that it is not necessary to re-invent the wheel but that it is about to build on what is already there

-Uses an existing risk management system if it is good

-Makes suggestions to improve the overall efficiency of sustainable procurement

-Suggests solutions: Are there alternatives that cost less? Can the own company and the supplier invest together? Are there subsidies from government?

- Checks if a common initiative with other customers could be initiated

-Cooperates with other customers of the supplier to benefit from the common purchasing power

-Thinks collaboratively to simplify processes

Competence name: Supplier relationship management (Holistic view) 


\section{Cognition-oriented SPSM competences}

\section{Definition:}

The competence to adopt a holistic view in supplier relationship management is the ability to understand motivators and restrictions for suppliers when implementing SPSM actors, the ability to systematically analyze the business environment of suppliers, and the ability to develop solutions

that meet different needs and requirements and promote SPSM at the same time

Observable behavior (based on CIs)

-Takes the supplier's point of view into consideration (win-win perspective)

-Understands risk

-Develops a plan and a timeline for sustainability that allows the supplier to develop economically at the same time

-Explains short-, mid- and long-term benefits (total value)

-Finds solutions how the supplier can save money

-Understands that helping suppliers to develop creates a long-term input and benefit

-Understands how the supplier could fulfil the requirements within the agreed prices/the existing financial framework of the business relationship

-Is open to accept the code of conduct of a supplier if it is a good one

Competence name: Systems thinking competence

\section{Definition:}

"Systems thinking is a framework for seeing wholes and a framework for seeing interrelationships rather than things, for seeing patterns of change rather than static snapshots" (Senge 1990). In the SPSM context, it includes the recognition of interdependencies within a supply chain network and the consideration of the impact when implementing a SPSM strategy

Opposite: Having a small view of the world

Observable behavior (based on CIs)

-Develops the business case for sustainability

-Understands circular economy models

-Is open to balance different requirements in the situation

- Gets the big picture and realizes the different needs and issues of the stakeholders

-Links corporate goals to PSM actions that support these goals

-Explains the contribution of PSM to a companies' sustainability strategy

-Contributes the PSM perspective to a complex interdisciplinary decision process

-Sees the connection between risk management and sustainability

-Understands how bad working conditions impact product quality

-Explains what non-compliance to environmental standards means to the supplier, the own company and the other companies in the industry in terms of risk

\section{Appendix F: social-oriented SPSM competences}

\section{Social-oriented SPSM competences}

Competence name: Communication skills

\section{Definition:}

This competence includes the ability to articulate and present sustainability issues in a convincing manner by applying appropriate communication styles and channels depend-

ing on target groups and situations

Observable behavior (based on CIs)

-Raises her/his voice and the issue

-Prepares well for convincing others

-Makes others understand what the issue is

-Articulates concerns

-Explains the own approach in an open and transparent manner

-Presents the own achievements and expertise according to the target group

-Presents PSM as a thoughtful partner

-Tries to find a common understanding

- Listens to concerns

-Looks for consensus

-Shows an open attitude for the conversation

-De-escalates in the meeting

-Reacts and behaves facts-based

-Negotiates

-Knows requirements for intercultural communication

-Uses the communication department to leverage the issue

Competence name: Cross-functional teamworking 


\section{Social-oriented SPSM competences}

\section{Definition:}

Cross-functional teamworking competence encompasses interpersonal and self-management knowledge, skills and abilities (Stevens and Campion 1994). In the SPSM context, it implies the knowledge about relevant stakeholders and partners, the skills to work in multi-disciplinary teams and the ability to establish relationships and liaisons with other functions within the organization

Observable behavior (based on CIs)

-Knows relevant internal departments to cooperate with

-Asks internal experts

-Keeps in close contact with others internally to make sure to be aligned

-Explains the sourcing situation (cost, sourcing capacity) to colleagues

-Establishes and uses a network internally and externally

-Cooperates with others to find common solutions

-Involves R\&D in the supplier selection process

-Includes expertise from other areas

- Convinces other departments that purchasing needs to be involved

-Is very clear towards product development and sustainability department what she/he can stand for

-Checks with legal and HR

-Cooperates with sustainability officer

Competence name: Interpersonally savvy

Definition:

Interpersonally savvy can be defined as "having a range of interpersonal skills and approaches and knowing when to use what with whom. The outcome is ease of transaction where you get what you need without damaging other parties unnecessarily and leave them wanting to work with you again" (Lombardo and Eichinger 2006, p. 265). For SPSM, this includes the ability to connect with others to discuss sustainability issues, to find peers that help promoting the topic and to adapt to different stakeholder representatives inside and outside the own organization

Observable behavior (based on CIs)

-Is smart and knows where and how to get information

-Builds strategic alliances

-Shows a sense for the reaction of the supplier in terms of how to interpret the supplier's reaction

-Anticipates how the different parties will behave and act

-Makes use of informal contacts with colleagues or the sustainability department to discuss the issue

-Asks experienced buyers if the own observations are conform with the company policy

- Goes through the right chain of demand: Speak to direct manager first

-Looks out for communication channels to the management to discuss non-compliance

-Speaks to the right contacts

\section{Competence name: Stakeholder management (Communication)}

\section{Definition:}

Stakeholder management can be defined as "[to] take into account the effects of your actions on others, as well as their potential effects on you. Doing so means you have to understand stakeholder behaviors, values, and back- grounds/contexts including the societal context." (Freeman 2004, p. 231). The competence to communicate with stakeholders includes the ability to articulate, explain and promote SPSM issues by applying appropriate communication styles towards different stakeholder groups*

* Excluding suppliers, as this is covered in Supplier relationship management (Communication) in this model, and excluding internal stakeholders, covered in 'Cross-functional teamworking'

Observable behavior (based on CIs)

- Realizes the gap between internal and external perception

-Refers to the concerns of stakeholders, e.g. NGOs

-Implements a pro-active communication strategy to avoid risk

-Sells the own activities to stakeholders, e.g. NGOs

-Explains the approach of PSM to internal stakeholders with the goal to find the best solution possible

-Explains to the NGO (if involved) the dependencies of the company on this supplier

- Connects with stakeholders and checks their expectation

-Asks NGOs very precisely about what exactly is the problem

-Spends time to listen to the relevant stakeholders

-Understands the internal problems and is able to translate those to the external party

- Accepts feedback from stakeholders

-Takes stakeholders, e.g. NGO representatives, seriously

- Shows vulnerability and shows the challenges in a transparent manner

-Discusses with stakeholders and finds out their knowledge on sustainability in their area

- Tries to get across to the stakeholders what the actual facts are

-Does not talk too much in a vague manner

-Is discreet towards the external environment

Competence name: Supplier relationship management (Communication) 


\section{Social-oriented SPSM competences}

\section{Definition:}

Communication competence in the context of supplier relationship management includes the ability

to articulate, explain and promote sustainability issues by applying appropriate communication styles

towards suppliers

Observable behavior (based on CIs)

-Explains to the supplier why the monitoring tools are implemented

-Is able to communicate the reasons for company decisions to suppliers

-Explains the process to the supplier before its implementation

- Talks to suppliers and explains that their contribution is needed and will probably result in a growing business also for them

- Communicates the consequences of non-compliance

-Explains the business risk for the supplier

-Explains clearly that in order to maintain the business relationship the supplier needs to work on implementing the sustainability standards

-Knows the cultural background of the country where a supplier is located

- Convinces suppliers based on facts

-Dares to speak up to the supplier

-Listens to the supplier

-Asks questions to the supplier

Competence name: Thoughtfulness towards others

\section{Definition:}

Thoughtfulness towards others in the SPSM context is about applying a certain attitude of respect when discussing the implementation of sustainability requirements with others, mainly suppliers in this context

Opposite: Being forceful, aggressive, emotional

Observable behavior (based on CIs)

-Shows understanding for the other position

-Asks the supplier what would allow the supplier more to comply with the standards

-Acts in a tactful manner

-Is open to balance different requirements in the situation

-De-escalates in the meeting

-Keeps calm

-Acts carefully

-Is aware how to avoid conflicts

•Follows up carefully

\section{Appendix G: meta-oriented SPSM competences}

\section{Meta-oriented SPSM competences}

\section{Competence name: Commitment to change}

\section{Definition:}

Commitment to change in the SPSM context is expressed by individual motivation and actions to implement

sustainability in PSM, and to be open and willing to change routines to enable the implementation

Observable behavior (based on CIs)

-Is passionate and believes in the benefit of sustainability

-Acts her-/himself

- Takes it serious if a supplier does not sign the code of conduct

-Draws motivation and a good feeling out of the engagement in sustainability activities

-Goes the extra mile to come to a good result

-Is willing to participate

-Deals with new tasks in a motivating manner

-Gets educated, e.g. asks to be trained in sustainability topics

-Takes on leadership to bring in new sustainability initiatives

-Comes up with ideas to solve the issue

-Gives the topic a high priority

-Does not follow a "heads down" attitude

-Is eager to learn

-Is open towards challenges

Competence name: Confidence 


\section{Meta-oriented SPSM competences}

\section{Definition:}

Confidence in the SPSM context includes a clear understanding of what needs to be done and not being afraid

to push for the desired result

Observable behavior (based on CIs)

-Does not make the sustainability standards of the company negotiable

-Explains to the supplier that as long there is any doubt, she/he will start to look for an alternative supplier

-Bears ambiguity

-Does not get scared

-Has the guts to ask questions and react

-Dares to speak up to the supplier

-Stands up for her/his professional role/interests

-Is able to say "This is not my responsibility"

\section{Competence name: Organizationally savvy}

\section{Definition:}

Organizationally savvy can be defined as the ability to understand organizational mechanics and to make use of this understanding to actively promote and implement SPSM

Observable behavior (based on CIs)

-Understands that SPSM implementation needs to be started at the right level within the company, and not at the individual level of a buyer

-Identifies roles and definitions in the company before doing the next step

-Knows where to get information

-Looks for support in the management

-Knows how hierarchy ticks

-Tries to create a more interesting role for PSM

-Makes sure that procurement is involved in strategy processes in the institution

-Identifies key people leading the project

-Takes a role as a gatekeeper

-Gives the assignment back if nobody is willing to cooperate

\section{Competence name: Persistence}

\section{Definition:}

Persistence in the SPSM context means to continuously stick to an issue and don't let it go without finding a solution, even when the situation in the supply network or within the own organization is complex and the

commitment of the involved stakeholders is low

\section{Observable behavior (based on CIs)}

-Puts pressure on the topic

-Insists to be involved

-Keeps on asking

-Digs deeper and deeper

-Tries to get involved, even if other functions do not understand the need to involve purchasing

-Follows the situation up closely

\section{Competence name: Politically savvy}

\section{Definition:}

Politically savvy can be defined as the ability to smoothly work with different stakeholders in complex political situations to achieve business objectives

Observable behavior (based on CIs)

-Actively uses the repertoire of company politics

-Tackles the task politically

-Does networking between decision makers (e.g. CEO - PSM-divisions)

-Acts diplomatically

-Balances interests

-Is smart and "street-wise" to find practical applications

-Is aware of the delicacy of some situations in the SPSM context

-Is aware that with sustainability one very often gets into a whole range of different problems/tensions

-Is able to deal with resistance

-Is looking for back-up to secure her-/himself

Competence name: Self-awareness 


\section{Meta-oriented SPSM competences}

\section{Definition:}

Self-awareness can be defined as the intrapersonal intelligence to know and handle one's own emotions,

needs, values and capabilities

Observable behavior (based on CIs)

-Is aware of own values

-Knows her/his individual threshold in coping with an unclear situation and knows how long she/he can stand this situation

-Is aware of own sphere of influence, competences and role

-Explains the own role: How can I help to achieve the goals and what are my limitations?

-Is aware of the impact of her/his own behavior

-Is able to say "This is not my responsibility"

-Trusts and follows up on the own feeling that something was not right

- Has a gut feeling and a conscience for working conditions

-Is aware how to avoid conflicts

-Follows up carefully

Competence name: Supplier relationship management (Cooperative approach)

\section{Definition:}

Supplier relationship management (Cooperative approach) is the ability and motivation to work together with the supplier in a supportive manner to reach SPSM goals, including the understanding of the benefit of

supplier cooperation

Observable behavior (based on CIs)

-Evaluates what to do together with the supply base to contribute to the corporate goals

-Develops the benefit together with the supplier

-Develops a roadmap with the supplier

- Coaches the supplier in the implementation of sustainability standards

-Gives expertise to suppliers

-Understands that there has to be something that is given to the suppliers for their sustainability engagement - e.g. higher volumes

-Identifies how to solve the situation together with the supplier

-Learns from suppliers

-Brings the supplier in contact with other experts

-Shares experiences with the supplier

-Expresses understanding for the situation of the supplier

- Helps to develop the supplier to a good stage in the expected requirements

•Helps the supplier to understand the issue

Author Contributions All authors contributed to the study conception and design. Material preparation, data collection and analysis were initially performed by Heike Schulze, supported by Lydia Bals and Jon Warwick. The first draft of the manuscript was written by Heike Schulze, Lydia Bals and Jon Warwick. All authors commented on previous versions of the manuscript. All authors read and approved the final manuscript.

Funding Open Access funding enabled and organized by Projekt DEAL. No funding received.

\section{Declarations}

\section{Conflicts of interest/Competing interests None}

Open Access This article is licensed under a Creative Commons Attribution 4.0 International License, which permits use, sharing, adaptation, distribution and reproduction in any medium or format, as long as you give appropriate credit to the original author(s) and the source, provide a link to the Creative Commons licence, and indicate if changes were made. The images or other third party material in this article are included in the article's Creative Commons licence, unless indicated otherwise in a credit line to the material. If material is not included in the article's Creative Commons licence and your intended use is not permitted by statutory regulation or exceeds the permitted use, you will need to obtain permission directly from the copyright holder. To view a copy of this licence, visit http://creativecommons.org/licenses/by/4.0/.

\section{References}

Aguinis H, Glavas A (2013) Embedded Versus Peripheral Corporate Social Responsibility: Psychological Foundations. Ind Organ Psychol 6(4):314-332

Bals L, Laine J, Mugurusi G (2018) Evolving Procurement Organizations: External and Internal fit Considerations. J Purch Supply Manag 24(1):41-58

Bals L, Schulze H, Kelly S, Stek K (2019) Purchasing and supply management (PSM) competencies: Current and future requirements. J Purch Supply Manag 25(5):10057

Bals L, Tate WL (2018) Sustainable supply chain design in social businesses: advancing the theory of supply chain. J Bus Logist 39(1):57-79

Bartram D, Robertson IT, Callinan M (2002) Introduction: A framework for examining organizational effectiveness: Organizational effectiveness: The role of psychology

Bartsch S, Specht N (2009) Die Critical Incident Technique (CIT). Theorien Und Methoden Der Betriebswirtschaft 377-400

Bocken NM, Short SW, Rana P, Evans S (2014) A literature and practice review to develop sustainable business model archetypes. J Clean Prod 65(4):42-56

Boyatzis RE (1982) The competent manager: A model for effective performance. John Wiley \& Sons, New York

Brannick MT, Cadle A, Levine EL (2012) Job analysis for knowledge, skills, abilities, and other characteristics, predictor measures, and performance outcomes. The Oxford Handbook of Personnel Assessment and Selection 119-146 
Briscoe JP, Hall DT (1999) Grooming and picking leaders using competency frameworks: Do they work? An alternative approach and new guidelines for practice. Organ Dyn 37

Busse C, Schleper MC, Niu M, Wagner SM (2016) Supplier development for sustainability: contextual barriers in global supply chains. Int J Phys Distrib Logist Manag 46(5):442-468

Campion MA, Fink AA, Ruggeberg B, Carr L, Phillips GM, Odman R (2011) Doing competencies well: Best practices in competency modelling. Pers Psychol 64(1):225-262

Caniato F, Caridi M, Crippa L, Moretto A (2012) Environmental sustainability in fashion supply chains: An exploratory case based research. Int J Prod Econ 135(2):659-670

Carter CR (2005) Purchasing social responsibility and firm performance: The key mediating roles of organizational learning and supplier performance. Int J Phys Distrib Logist Manag 35(3):177-194

Dalton M (1997) Are competency models a waste?. Training \& Development 51(10):46-50

Delamare Le-Deist F, Winterton J (2005) What is competence?. Hum Resour Dev Int 8(1):27-46

Derwik P, Hellström D, Karlsson S (2016) Manager competences in logistics and supply chain practice. J Bus Res 69(11):4820-4825

Durach CF, Kembro J, Wieland A (2017) A new paradigm for systematic literature reviews in supply chain management. J Supply Chain Manag 53(4):67-85

Dzhengiz T, Niesten E (2020) Competences for environmental sustainability: A systematic review on the impact of absorptive capacity and capabilities. J Bus Ethics 162(4):881-906

Easterby-Smith M, Thorpe R, Jackson PR (2008) Management research: An introduction. Sage, Thousand Oaks

Erpenbeck J (2013) Zwischen exakter Nullaussage und vieldeutiger Beliebigkeit Hybride Kompetenzerfassung als künftiger Königsweg. Kompetenzmodelle von Unternehmen. Schäffer-Poeschel Verlag, Stuttgart

Etse D, McMurray A, Muenjohn N (2021) The Effect of Regulation on Sustainable Procurement: Organisational Leadership and Culture as Mediators. J Bus Ethics 1-21

European Commission (2020) Study on due diligence requirements through the supply chain, European Commission Report: European Commission Report. Retrieved from https://op.europa.eu/ de/publication-detail/-/publication/8ba0a8fd-4c83-11ea-b8b701aa75ed71a1/language-en

Faes W, Knight L, Matthyssens P (2001) Buyer profiles: an empirical investigation of changing organizational requirements. Eur J Purch Supply Manag 7(3):197-208

Fayezi S, Zomorrodi M, Bals L (2018) Procurement sustainability tensions: an integrative perspective. Int J Phys Distrib Logist Manag 48(6):586-609

Flanagan JC (1954) The critical incident technique. Psychol Bull 51(4):327

Flöthmann C, Hoberg K, Gammelgaard B (2018) Disentangling supply chain management competencies and their impact on performance: A knowledge-based view. Int J Phys Distrib Logist Manag 48(6):630-655

Fraser IJ, Müller M, Schwarzkopf J (2020a) Transparency for multi-tier sustainable supply chain management: A case study of a multitier transparency approach for SSCM in the automotive industry. Sustainability 12(5):1814

Fraser IJ, Schwarzkopf J, Müller M (2020b) Exploring supplier sustainability audit standards: potential for and barriers to standardization. Sustainability 12(19):8223

Freeman RE (2004) The stakeholder approach revisited. Zeitschrift Für Wirtschafts- Und Unternehmensethik 5(3):228-254

Galleli B, Hourneaux Junior F (2019) Human competences for sustainable strategic management: evidence from Brazil. Benchmark Int J
Galleli B, Hourneaux Junior F (2020) Sustainability and human competences: a systematic literature review. Benchmark Int J 27(7):1981-2004

Giunipero LC, Dawley D, Anthony WP (1999) The impact of tacit knowledge on purchasing decisions. J Supply Chain Manag 35(4):42-49

Giunipero LC, Denslow D, Eltantawy R (2005) Purchasing/supply chain management flexibility: Moving to an entrepreneurial skill set. Ind Mark Manag 34(6):602-613

Giunipero LC, Handfield RB, Eltantawy RA (2006) Supply management's evolution: key skill sets for the supply manager of the future. Int J Oper Prod Manag 26(7):822-844

Giunipero LC, Hooker RE, Denslow D (2012) Purchasing and supply management sustainability: Drivers and barriers. J Purch Supply Manag 18(4):258-269

Giunipero LC, Pearcy DH (2000) World-class purchasing skills: An empirical investigation. J Supply Chain Manag 36(3):4-13

Goebel P, Reuter C, Pibernik R, Sichtmann C, Bals L (2018) Purchasing managers' willingness to pay (WTP) for attributes that constitute sustainability. J Oper Manag 62(6):44-58

González-Benito J (2007) A theory of purchasing's contribution to business performance. J Oper Manag 25(4):901-917

Grote S, Kauffeld S, Frieling E (2012) Kompetenzmanagement. Schäffer-Poeschel Verlag, Stuttgart

Häder M (2014) Delphi-Befragungen. Ein Arbeitsbuch. SpringerVerlag, Wiesbaden

Hanning A, Abelsson AP, Lundqvist U, Svanström M (2012) Are we educating engineers for sustainability?. Comparison between obtained competences and Swedish industry's needs. Int J Sustain High Educ 13(3):305-320

Harms D, Hansen EG, Schaltegger S (2013) Strategies in sustainable supply chain management: an empirical investigation of large German companies. Corp Soc Responsib Environ Manag 20(4):205-218

Hoberg K, Thornton L, Wieland A (2020) How to deal with the human factor in supply chain management?. Int J Phys Distrib Logist Manag 50(2):151-158

Hofmann H, Schleper MC, Blome C (2015) Conflict minerals and supply chain due diligence: An exploratory study of multi-tier supply chains. J Bus Ethics 147(1):115-141

Hohenstein NO, Feisel E, Hartmann E (2014) Human resource management issues in supply chain management research: A systematic literature review from 1998 to 2014. Int J Phys Distrib Logist Manag 44(6):434-463

Johnsen TE, Howard M, Miemczyk J (2014) Purchasing and supply chain management: A sustainability perspective. Routledge, London/New York

Katz RL (1974) Skills of an Effective Administrator. Harv Bus Rev 52(5):90-102

Kern D, Moser R, Sundaresan N, Hartmann E (2011) Purchasing competence: A stakeholder-based framework for chief purchasing officers. J Bus Logist 32(2):122-138

Knight L, Tate WL, Ellram LM, Salmi A, van Raaij E, Wagner SM (2019) Looking Back \& Looking Forward. J Purch Supply Manag 100582

Knight L, Tu YH, Preston J (2014) Integrating skills profiling and purchasing portfolio management: An opportunity for building purchasing capability. Int J Prod Econ 147:271-283

Kolb M, Fröhlich L, Schmidpeter R (2017) Implementing sustainability as the new normal: Responsible management education-From a private business school's perspective. J Manag Educ 15(2):280-292

Krause DR, Pagell M, Curkovic S (2001) Toward a measure of competitive priorities for purchasing. J Oper Manag 19(4):497-512

Krumm S, Mertin I, Dries C (2012) Kompetenzmodelle. Hogrefe, Göttingen 
Lambrechts W, Mulá I, Ceulemans K, Molderez I, Gaeremynck V (2013) The integration of competences for sustainable development in higher education: An analysis of bachelor programs in management. J Cleaner Prod 48(65-73)

Lincoln YS, Guba EG (1985) Naturalistic Inquiry. Sage publications, Newbury Park, CA

Linstone HA, Turoff M (2011) Delphi: A brief look backward and forward. Technol Forecast Soc Chang 78(9):1712-1719

Lombardo MM, Eichinger RW (2006) The career architect development planner. Lominger Limited, Minneapolis, MN

Luzzini D, Brandon-Jones E, Brandon-Jones A, Spina G (2015) From sustainability commitment to performance: The role of intra- and inter-firm collaborative capabilities in the upstream supply chain. Int J Prod Econ 165:51-63

Mansfield RS (1996) Building competency models: Approaches for HR professionals. Hum Resour Manage 35(1):7-18

Marshall D, McCarthy L, McGrath P, Claudy M (2015) Going above and beyond: how sustainability culture and entrepreneurial orientation drive social sustainability supply chain practice adoption. Supply Chain Manag: Int J 20(4):434-454

Maxwell JA (1997) Designing a qualitative study: Handbook of applied social research methods. Sage publications, London

Mayring P (1993) Qualitative Inhaltsanalyse. Grundlagen und Techniken (4th ed.). Beltz Weinheim/Basel

McClelland DC (1998) Identifying competencies with behavioral-event interviews. Psychol Sci 9(5):331-339

Miemczyk J, Johnsen TE, Macquet M (2012) Sustainable purchasing and supply management: a structured literature review of definitions and measures at the dyad, chain and network levels. Supply Chain Manag Int J 17(5):478-496

Mintzberg H (1973) The nature of managerial work. Prentice Hall, London

Mochizuki Y, Fadeeva Z (2010) Competences for sustainable development and sustainability: significance and challenges for ESD. Int J Sustain High Educ 11(4):391-403

Monczka RM, Handfield RB, Guinipero LC, Patterson JL, Waters D (2016) Purchasing \& supply chain management. Cengage Learning, London

Montabon F, Pagell M, Wu Z (2016) Making sustainability sustainable. J Supply Chain Manag 52(2)11-27

Muff K, Liechti A, Dyllick T (2020) How to apply responsible leadership theory in practice: A competency tool to collaborate on the sustainable development goals. Corp Soc Responsib Environ Manag 27(5):2254-2274

Nonaka I, Takeuchi H (1995) The Knowledge-creating Company: How Japanese Companies Create the Dynamics of Innovation. Oxford University Press, Oxford

O'Marah K (2015) Supply Chain organizational design: structure for balance. SCM World

Osagie ER, Wesselink R, Blok V, Lans T, Mulder M (2016) Individual Competences for Corporate Social Responsibility: A Literature and Practice Perspective. J Bus Ethics 135(2):233-252

Pagell M, Shevchenko A (2014) Why research in sustainable supply chain management should have no future. J Supply Chain Manag 50(1):44-55

Pagell M, Wu Z (2009) Building a more complete theory of sustainable supply chain management using case studies of 10 exemplars. J Supply Chain Manag 45(2):37-56

Parks-Leduc L, Mulligan L, Rutherford MA (2020) Can ethics be taught? Examining the Impact of Distributed Ethical Training and Individual Characteristics on Ethical Decision Making. Academy of Learning \& Education

Preuss L (2009) Ethical sourcing codes of large UK-based corporations: prevalence, content, limitations. J Bus Ethics 88(4):735-747

Rahbek E, Pedersen G (2015) Corporate Social Responsibility. Sage Publications Ltd, London
Salman M, Ganie SA, Saleem I (2020) The concept of competence: a thematic review and discussion. Eur J Train Dev

Schiele H (2012) Accessing supplier innovation by being their preferred customer. Res Tech Manag 55(1):44-50

Schiele H (2010) Early supplier integration: the dual role of purchasing in new product development. R\&d Manag 40(2):138-153

Schneider L, Wallenburg CM (2012) Implementing sustainable sourcing Does purchasing need to change?. J Purch Supply Manag 18(4):243-257

Schuler H (2014) Arbeits- und Anforderungsanalyse. In: Schuler H, Kanning UP (eds) Lehrbuch der Personalpsychologie. Hogrefe, Göttingen, pp 61-97

Schulze H, Bals L (2020) Implementing sustainable purchasing and supply management (SPSM): A Delphi study on competences needed by purchasing and supply management (PSM) professionals. J Purch Supply Manag, forthcoming

Schulze H, Bals L, Johnsen TE (2019) Individual competences for sustainable purchasing and supply management (SPSM). Int J Phys Distrib Logist Manag 49(3):287-304

Senge P (1990) The fifth discipline. Currency Doubleday, New York

Sinkovics RR, Penz E, Ghauri PN (2005) Analysing textual data in international marketing research. Qual Mark Res: Internat J 8(1):9-38

Shippmann JS, Ash RA, Batjtsta M, Carr L, Eyde LD, Hesketh B (2000) The practice of competency modeling. Pers Psychol 53(3):703-740

Smith G (2002) Are There Domain-Specific Thinking Skills?. J Philos Educ 36(2):207-227

Spencer LM, Spencer SM (1993) Competence at work: Models for superior performance. Wiley \& Sons, New York

Strauss A, Corbin J (1994) Grounded theory methodology. Handbook Qual Rese 17:273-285

Stevens MJ, Campion MA (1994) The knowledge, skill, and ability requirements for teamwork: Implications for human resource management. J Manag 20(2):503-530

Tassabehji R, Moorhouse A (2008) The changing role of procurement: Developing professional effectiveness. J Purch Supply Manag 14(1):55-68

The Case Centre (2017) Bringing sustainability metrics to purchasing decisions. Retrieved from http://www.thecasecentre.org

Tranfield D, Denyer D, Smart P (2003) Towards a methodology for developing evidence-informed management knowledge by means of systematic review. Br J Manag 14(3):207-222

UNGC (2017) Apply sustainable practices throughout the supply chain. Retrieved from https://www.unglobalcompact.org/what-is-gc/ our-work/supply-chain

UNGC, GRI, WBSC (2015) SDG Compass - The guide for business action on the SDGs. Retrieved from https://sdgcompass.org/wpcontent/uploads/2015/12/019104_SDG_Compass_Guide_2015.pdf

United Nations (2020) Progress towards the Sustainable Development Goals: Report of the Secretary-General. Retrieved from https:// www.un.org/ga/search/view_doc.asp?symbol=E/2020/57

Van Weele AJ (2014) Purchasing and Supply Chain Management: Analysis, Strategy. Planning and Practice. Cengage Learning, London

Van Weele AJ (2010) Purchasing and supply chain Management: Analysis, strategy, planning and practice. Cengage Learning, London

Villena VH (2019) The missing link?. The strategic role of procurement in building sustainable supply networks. Prod Oper Manag 28(5):1149-1172

Von Rosenstiel L (2011) Employee behaviour in organizations. On the current state of research. Manag Rev 22(4):344-366

Von Rosenstiel L, Koch S (2003) Change in socioeconomic values as a trigger of organizational learning. Handbook of organizational learning and knowledge. Oxford University Press, Oxford

Walker H, Brammer S (2012) The relationship between sustainable procurement and e-procurement in the public sector. Int J Prod Econ 140(1):256-268 
Wiek A, Withycombe L, Redman CL (2011) Key competencies in sustainability: a reference framework for academic program development. Sustain Sci 6(2):203-218

Wieland A, Handfield RB, Durach CF (2016) Mapping the landscape of future research themes in supply chain management. J Bus Logist 37(3):205-212

Willard M, Wiedmeyer C, Flint RW, Weedon JS, Woodward R, Feldmand I, Edwards M (2010) The sustainability professional: 2010 competency survey report: Environmental Quality Management.
Yawar SA, Seuring S (2018) The role of supplier development in managing social and societal issues in supply chains. J Clean Prod 182(13):227-237

Zadek S (2004) The Path to Corporate Responsibility. Harv Bus Rev 82(12):125-132

Publisher's Note Springer Nature remains neutral with regard to jurisdictional claims in published maps and institutional affiliations. 